\title{
A regional and nonstationary model for partial duration series of extreme rainfall
}

\author{
Gregersen, Ida Bülow; Madsen, Henrik; Rosbjerg, Dan; Arnbjerg-Nielsen, Karsten
}

Published in:

Water Resources Research

Link to article, DOI:

10.1002/2016WR019554

Publication date:

2017

Document Version

Peer reviewed version

Link back to DTU Orbit

Citation (APA):

Gregersen, I. B., Madsen, H., Rosbjerg, D., \& Arnbjerg-Nielsen, K. (2017). A regional and nonstationary model for partial duration series of extreme rainfall. Water Resources Research, 53(4), 2659-2678.

https://doi.org/10.1002/2016WR019554

\section{General rights}

Copyright and moral rights for the publications made accessible in the public portal are retained by the authors and/or other copyright owners and it is a condition of accessing publications that users recognise and abide by the legal requirements associated with these rights.

- Users may download and print one copy of any publication from the public portal for the purpose of private study or research.

- You may not further distribute the material or use it for any profit-making activity or commercial gain

- You may freely distribute the URL identifying the publication in the public portal

If you believe that this document breaches copyright please contact us providing details, and we will remove access to the work immediately and investigate your claim 


\section{A REGIONAL AND NON-STATIONARY MODEL FOR PARTIAL \\ 2 DURATION SERIES OF EXTREME RAINFALL}

3

4 Ida Bülow Gregersen

5 Department of Environmental Engineering, Technical University of Denmark, Bygningstorvet, $6 \quad$ Building 115, DK-2800 Lyngby

7 Presently working at:

8 Ramboll, Hannemanns Allé 53, DK-2300 Kbh S

9 idbg@env.dtu.dk

Henrik Madsen

DHI, Agern Alle 5, DK-2970 Hørsholm

hem@dhigroup.com

\section{Dan Rosbjerg}

Department of Environmental Engineering, Technical University of Denmark, Bygningstorvet, Building 115, DK-2800 Lyngby

daro@env.dtu.dk

\section{Karsten Arnbjerg-Nielsen}

Department of Environmental Engineering, Technical University of Denmark, Bygningstorvet, Building 115, DK-2800 Lyngby

karn@env.dtu.dk

\section{ABSTRACT}

Regional extreme value models for estimation of extreme rainfall intensities are widely applied, but

their underlying assumption of stationarity is challenged. Many recent studies show that the rainfall extremes worldwide exhibit a non-stationary behavior. This paper presents a spatio-temporal model of extreme rainfall. The framework is built on a Partial Duration Series approach with a nonstationary, regional threshold value. The model is based on Generalized Linear Regression solved 
by Generalized Estimation Equations. It allows a spatial correlation between the stations in the network and accounts furthermore for variable observation periods at each station and in each year. Marginal regional and temporal regression models solved by Generalized Least Squares are used to validate and discuss the results of the full spatio-temporal model.

The model is applied on data from a large Danish rain gauge network for four durations ranging from 10 minutes to 24 hours. The observation period differs between stations, and the number of stations with more than 10 years of observations has increased over the years. A spatio-temporal model for the threshold is suggested, applying the Mean Annual Precipitation and time as the explanatory variables in the regional and temporal domain, respectively. Further analysis of Partial Duration Series with non-stationary and regional thresholds shows that the mean exceedances also exhibit a significant variation in space and time for some rainfall durations, while the shape parameter is found to be constant.

\section{INTRODUCTION}

Non-stationary extreme value frameworks for estimation of design rainfall or design floods have received increased attention along with the numerous reports of observed trends in extreme rainfall and flood statistics [e.g. Min et al., 2011; Westra et al., 2013; Sun et al., 2015; Madsen et al., In Review]. Regional extreme value models for extreme rainfall have been applied in many countries, e.g. Denmark, Norway, UK, Canada and Australia [Madsen et al., 2002; Dyrrdal et al., 2014; Fowler and Kilsby, 2003; Wallis et al., 2007; Haddad et al., 2011]. Several frameworks for regional modelling exist, built on different principles. The most traditional is the index-flood model, which became widely applied after the advancement of the regional L-moment approach by Hosking and Wallis [1993]. In this framework the uncertainty of the estimated at-site design events is reduced by the estimation of regional extreme value distribution (EVD) parameters from a homogenous region. 
54 The index-flood model was originally applied for annual maxima extremes in a stationary setting. Later advancements include an extension to Peak over Threshold (POT) data [Haddad et al., 2011; Madsen and Rosbjerg, 1997] based on Generalized Least Squares (GLS) estimation procedures [Stedinger and Tasker 1985] where the variability of the EVD parameters is modelled by regional covariates. This framework accounts for both at-site sampling uncertainty and spatial dependencies between the observations at different sites. Regarding non-stationarity of the parameters of the EVD, Gregersen et al. [2013a] presented a model for the spatio-temporal variation of the number of extreme events building on the framework of Generalized Linear Models (GLM), while Roth et al. [2012] used the POT-threshold as the index variable and allowed it to vary in both time and space. As discussed by Kyselý et al. [2010], a non-stationary threshold is crucial when having a nonuniform distribution of extreme events over the observation period, because the otherwise variable intensity of the Poisson process will violate the asymptotic properties of the POT model. Suitable non-stationary threshold models are often found by quantile regression [Kyselý et al., 2010; Roth et al., 2012].

A drawback of the regression based index flood method is that inferences are made on statistics derived from the observations and not from the observations directly [Renard, 2011]. Some authors prefer another type of regional model based on hierarchical principles, which overcomes this problem. In the hierarchical model prior distributions are defined for each of the parameters in the EVD [e.g. Aryal et al., 2009; Dyrrdal et al., 2014; Ghosh and Mallick, 2011; Heaton et al., 2011; Renard, 2011; Sun et al., 2015]. From here there are numerous possibilities with regard to the specific model formulation and the parameter estimation algorithms. Hierarchical extreme value models are often solved by sampling algorithms like the Markov Chain Monte Carlo method [Cooley, 2007; Dyrrdal et al., 2014; Ghosh and Mallick, 2011; Renard, 2011]. Recently, an 
alternative approach based on the max-stable framework solved by composite likelihood has gained attention [Thibaud et al., 2013; Westra and Sisson, 2011]. Roth et al. [2012] also applied composite likelihood but on an index-flood model derived from POT data. Like the hierarchical model, both models can include regional and temporal variability in a dataset with a spatial correlation structure.

Regarding regional variations in the parameters some authors use a Kriging technique [Aryal et al., 2009], a trivariate Gaussian process with an exponential, distance depending covariance function [e.g. Cooley, 2007; Heaton et al., 2011] or a combination of the latter and regression to regional covariates [e.g. Dyrrdal et al., 2014; Ghosh and Mallick, 2011; Renard, 2011). Temporal variations are also assessed together with their influence on the regionalization [e.g. Aryal et al., 2009; Ghosh and Mallick, 2011; Heaton et al., 2011; Renard, 2006; Roth et al., 2012; Sun et al., 2015; Westra and Sisson, 2011]. Some of these studies include spatial dependencies between the observations at different locations. This can be numerically and theoretically difficult, but with a dense network the uncertainty of the model parameters is greatly underestimated, if the joint probability of observing a given extreme at several sites is disregarded [Roth et al., 2012; Westra and Sisson, 2011]. Joint probabilities can be described by copula functions, which therefore can be included in the hierarchical models to account for the spatial dependencies [Ghosh and Mallick, 2011; Renard, 2011]. Sun et al. [2015] developed a description applicable for a network of flow measurement stations along a branched river. In a max-stable process for extreme rainfall, spatial dependence on the data level is accounted for by a storm profile model, which is naturally incorporated in the framework [Thibaud et al., 2013; Westra and Sisson, 2011].

9 The salient point in all above-mentioned non-stationary approaches is the description of the spatial dependencies and, most importantly, the assumptions enforced to solve the complicated equation 
structure it entails. This becomes particularly difficult for a model based on POT data from a rain gauge network with a varying number of annually active stations, though Ghosh and Mallick [2011], Roth et al. [2012] and Thibaud et al. [2013] show very promising results.

The purpose of this paper is to extend the regression based index flood model solved by GLS [Madsen and Rosbjerg, 1997] that is currently applied in Denmark for regional estimation of extreme rainfall [Madsen et al., 2002; 2009; In Review) to include a temporal dimension. The procedure developed comprises a GLM solved by the Generalized Estimation Equations (GEE) approach applied by Gregersen et al. [2013a] but now extended to more parameters of the EVD. Preliminary analyzes of the temporal and regional variations are performed by marginal models as in Gregersen et al. [2013a]. The first analysis aims to formulate a non-stationary threshold model. The quantile regression approach is inapplicable due to the independence criteria traditionally applied for this type of rainfall data (see Section 3 for details). Subsequently, the threshold model is validated and applied. Finally, regional and temporal variations of EVD parameters are assessed. All calculations are performed for four different rainfall durations relevant for urban drainage design.

\section{Methodology}

\subsection{Partial Duration Series AND REgiOnal ESTIMATION OF EXTREME RAINFALl}

The extreme value analysis follows the theory of Partial Duration Series (PDS) where the annual number of extreme events $(N)$ is assumed to follow a Poisson distribution with rate parameter $(\lambda)$,

$$
P\{N=n\}=\frac{\lambda^{n}}{n !} e^{-\lambda}, \quad N=0,1,2 \ldots
$$

and the magnitude of the extreme events $(\mathrm{z})$ is assumed to follow a Generalized Pareto Distribution (GPD) with a location $(\beta)$, a scale $(\alpha)$ and a shape $(\kappa)$ parameter 


$$
F(z)=P\{Z \leq z\}=1-\left(1+\kappa \frac{z-\beta}{\alpha}\right)^{1 / \kappa}
$$

[Coles, 2001; Rosbjerg et al., 1992]. When sampling the extreme events from a time series, the PDS approach offers two censoring methods [Mikkelsen et al., 1995]. In type 1 censoring, the threshold $\left(z_{0}\right)$ over which an event is considered as extreme is pre-fixed. The method is also known as Peak over Threshold [Coles, 2001]. In this case $z_{0}$ replaces $\beta$ in the GPD in Eq. (2). All other parameters in Eq. (1) and Eq. (2) are estimated from the dataset. In type 2 censoring, $\lambda$, and thereby the total number of extremes during the observation period, is pre-fixed. In this case all parameters in Eq. (2) are estimated from the dataset.

The extreme events in the PDS are required to be independent [Coles, 2001]. In the literature there are at least two common ways of ensuring this. Many studies perform a declustering procedure based only on the time span between the extreme events [e.g. Ghosh and Mallick, 2011; Roth et al., 2012], while Madsen et al. [2002] performed an event-based separation using information on the dry-weather period. This method is particularly useful for tipping bucket rainfall measurements, where the observations are stored as events (see Section 3).

The procedures from Madsen et al., [2002] are applied here. Therefore, two rainfall events are independent if the dry weather period between them is longer than or equal to the analyzed rainfall duration. This event-based separation procedure is performed prior to the PDS approach and is therefore valid independent of the selected PDS censoring. Available for the extreme value analysis is therefore a series of independent events $(\boldsymbol{Y})$ represented by the maximum mean intensity of the event $(y)$ for a given duration, and the start and termination time $\left(t_{\text {start }}, t_{\text {end }}\right)$ for the event for each 
143 144 defined

$$
\not u=b_{0} \quad \text { and } \quad \hat{L}_{c v}=\frac{b_{1}}{b_{0}}
$$

$154 \kappa$ of the GPD is directly related to $L_{c v}$

$$
\hat{\kappa}=\frac{1}{\hat{L}_{c v}}-2
$$

155 while $\alpha$ of the GPD is estimated from $\mu_{\mu}$ and $\hat{L}_{C V} \quad$ [Hosking, 1990]. Madsen et al. (2002, 2009, 156 In Review) showed that $\lambda$ and $\mu$ exhibit significant regional patterns, while $L_{C V}$ and thereby $\kappa$ is 157 homogeneous over the region. This gives the following estimate of a regional T-year event

$$
\hat{z}_{T, s}=z_{0}+\mu_{s} \frac{1+\hat{\kappa}_{R}}{\hat{\kappa}_{R}}\left[1-\left(\frac{1}{\hat{\lambda}_{s} T}\right)^{\hat{\kappa}_{R}}\right]
$$

158 where index $s$ refers to a site-specific estimate and $R$ to a regional estimate. As discussed in the 159 introduction, a clear shortcoming of this model is that temporal variations are not accounted for. 
The first step pursued in this paper is to develop a spatio-temporal model for $\beta$, which can be applied on the series of independent rainfall events. With a method to describe and evaluate this variability, it is possible to define a model for $z_{0}$, which will ensure that $\lambda$ does not exhibit significant variations over time and space. The second step is to apply the threshold model and analyze the remaining variability in the GDP parameters.

\subsubsection{A SPATIO-TEMPORAL MODEL FOR $\beta$}

A PDS is defined from $Y$ using type 2 censoring, $P D S_{2}$. The rate parameter of the Poisson distribution is prefixed ( $\lambda=4$ events/year). The choice of rate parameter is based on experience from earlier studies (Madsen et al., [2002, 2009]).]. Since the aim is to capture the regional and temporal variation, the censoring is performed for each year individually. From $P D S_{2} \beta$ is estimated for each year, $i$, and each site, $s$, as the minimum exceedance in a year. A regression model is constructed for $\beta_{i, s}$ evaluating both regional and temporal variations, following the procedures described in Section 2.2 and 2.3.

\subsubsection{TYPE 1 CENSORING APPLYING A TIME-DEPENDENT AND REGIONAL THRESHOLD}

The model for $\beta$ found in the first step is applied as a deterministic model for $z_{0}$. On this basis a new PDS is defined from $\boldsymbol{Y}$ using type 1 censoring with a pre-fixed $z_{0}$ that varies in time and space. In the following this PDS is denoted $P D S_{l}$. The properties of $P D S_{1}$ is validated by assessing the variability of $\lambda . \lambda$ is a random variable in the model, but $\lambda$ should not exhibit any significant variations in time and space, since this variability is explained by the variation in $z_{0}$. Therefore a regional estimate of $\lambda$ can be applied. $\mu$ and $L_{C V}$ are also estimated from $P D S_{I}$ and their regional and temporal variation is assessed following the procedures described in Section 2.2 and 2.3.

In each of the two steps marginal models are obtained by averaging over either time $i$ or space $s$. After this a full spatio-temporal model is developed based on GLM solved by GEE as in Gregersen 
et al. [2013a]. In both the full model and the marginal models knowledge on the correlation between the rain gauge stations is required.

186

187 188

\subsection{MARGINAL MODELS}

The general procedures behind the marginal GLS models are similar for all the analyzed GDP parameters: $\beta$ from $P D S_{2}$ and $\lambda, \mu$ and $L_{C V}$ from $P D S_{1}$. The following description of the methodology applied to assess the variation in space and time, respectively, focuses on $\beta$. When relevant, conditions that make the approach different for one of the other variables are highlighted.

\subsubsection{MARGINAL MODEL FOR VARIATION IN SPACE}

Site specific estimates of $\beta$ are obtained from an average over all years of observation at the site

$$
\beta_{s}=\frac{\sum_{i=1}^{M_{s}} \beta_{i, s}}{M_{s}}
$$

The average of a given quantity asymptotically follows a normal distribution, so analyzes of $\beta_{s}$ can be based on linear regression. GLS is applied to include a possible spatial correlation between the observations and a weighting that reflects the sampling uncertainty, which for a specific site $s$ is related to the total period of observation $l_{s}$ or the total number of observations $n_{s}$ at that location.

The following regression model is tested

$$
\beta_{s}=\boldsymbol{X} \boldsymbol{B}_{\beta s}+\boldsymbol{\varepsilon}_{\Sigma}
$$

where $\boldsymbol{X}$ is a matrix of regional covariates, $\mathbf{B}_{\beta s}$ is the regression parameters, and $\Sigma$ is the variancecovariance matrix of the model residuals $\varepsilon$. The following structure of $\Sigma$ is assumed in the GLS model of $\boldsymbol{\beta}_{\text {s }}$ 


$$
\Sigma=\left[\begin{array}{ccccc}
\sigma_{\varepsilon 1}^{2}+\sigma_{\delta}^{2} & \sigma_{\varepsilon 1} \sigma_{\varepsilon 2} \rho_{12} & \cdots & & \sigma_{\varepsilon 1} \sigma_{\varepsilon K} \rho_{1 K} \\
\sigma_{\varepsilon 2} \sigma_{\varepsilon 1} \rho_{21} & \sigma_{\varepsilon 2}^{2}+\sigma_{\delta}^{2} & & & \sigma_{\varepsilon 2} \sigma_{\varepsilon K} \rho_{2 K} \\
\vdots & & \ddots & \sigma_{\varepsilon s} \sigma_{\varepsilon k} \rho_{s k} & \vdots \\
& & \sigma_{\varepsilon k} \sigma_{\varepsilon s} \rho_{k s} & & \\
\sigma_{\varepsilon K} \sigma_{\varepsilon 1} \rho_{K 1} & \sigma_{\varepsilon K} \sigma_{\varepsilon 2} \rho_{K 2} & \cdots & & \sigma_{\varepsilon K}^{2}+\sigma_{\delta}^{2}
\end{array}\right]
$$

In the matrix $\sigma_{\varepsilon}$ represents the sampling uncertainty, $\sigma_{\delta}$ the residual uncertainty in the regression model, and $\rho$ the spatial correlation. $\sigma_{\delta}$ is assumed to be unknown and is estimated along with the other variables in the regression model. The estimation of $\rho$ is described in the following section, while $\sigma_{\varepsilon}$ is a function of the variance of $\beta_{s}$ and $l_{s}$.

A description of $\sigma_{\varepsilon}$ for each of the analyzed extreme value statistics is given in Appendix A.1. For $\beta_{s}, \sigma_{\varepsilon}$ is estimated as

$$
\hat{\sigma}_{\varepsilon s}^{2}=\frac{c}{l_{s}} \quad \text { where } \quad c=\frac{1}{K} \sum_{s=1}^{K}\left(\frac{\sum_{i=1}^{M_{s}}\left(\beta_{i, s}-\overline{\beta_{s}}\right)^{2}}{M_{s}-1}\right)
$$

where $\bar{\beta}$ is the average over all sites.

A similar procedure is applied for $\lambda_{s}$ and $\mu_{s}$, while for $L_{C V s}$ Monte Carlo simulations are applied (see Appendix A.1). All estimation procedures of $\sigma_{\varepsilon}$ assume stationarity over time.

For comparison, ordinary linear regression (OLS) is also applied for the estimation of $\mathbf{B}_{\beta S}$. In OLS both sampling uncertainty and spatial correlation are disregarded. Furthermore, the statistical significance of the explanatory variables is evaluated by a t-test on the ratio between the regression slope and its standard deviation. A similar quantity can be estimated for GLS, but here it is also important to assess $\sigma_{\delta}$ both in the regression model and in an intercept model, i.e. where only the 
intercept is included in Eq.(8). If $\sigma_{\delta}$ is close to zero in the intercept model or negative, all variability is accounted for by the estimated sampling uncertainty, and explanatory variables cannot contribute to a further reduction. Likewise, the value of $\sigma_{\delta}$ in the regression model can be used to assess the amount of unexplained variability.

\subsubsection{CORRELATION BETWEEN RAIN GAUGE STATIONS}

A framework that estimates the spatial dependence between extreme rainfall events at individual rain gauge stations has been developed by Mikkelsen et al. [1996] for PDS. It is applied to obtain a robust, regional estimation of the correlation structure to be used in $\Sigma$, see Eq. (9). To ensure this, the spatial correlation, $\rho$, of the GPD parameters is first estimated from the data, and subsequently, described by a parametric correlation model. For further discussion, see Madsen and Rosbjerg [1997].

For $\beta$ and $\lambda, \rho$ is estimated from annual time series of $\beta_{i, s}$ for all pairs of stations. If a rain gauge has 231 long periods of malfunction during a year, it will affect the estimate of $\beta_{i, s}$ and hence $\rho$. Therefore 232 individual station years are removed from the analysis if the total observation period in a given year 233 is less than 300 days. For $\mu$ a method is used, which pairs events that in a physical sense can be 234 regarded concurrent. This is done for each pair of stations, based on $t_{\text {start }}$ of the events combined 235 with a lag time, which accounts for the travelling time of the weather systems. For details the reader 236 is referred to Gregersen et al. [2013b] and Mikkelsen et al. [1996]. Finally, the correlogram is 237 estimated by averaging $\rho$ over distance intervals and subsequently described by an exponential 238 model. 
Annual estimates of $\beta$ are obtained from an average over all stations. Due to the correlation between

241 the stations in the network a weighted average is applied so the influence of station clusters with 242 similar properties is reduced

$$
\beta_{i}=\frac{\sum_{s=1}^{K_{i}} \beta_{i, s} w_{s}}{K_{i}}
$$

243 The applied weights $\left(w_{s}\right)$ are estimated for each station as one minus the average correlation 244 coefficient between the given station and all other stations in the network. High weights are given to 245 stations with low average correlation, and all weights sum to one.

247 As in Section 2.2.1, analyzes of $\beta_{i}$ can be based on linear regression, where GLS is applied to 248 include a weighting that reflects the sampling uncertainty. Temporal correlation is discarded, as it is 249 assumed that the estimates of $\beta_{i}$ are independent from year to year. The sampling uncertainty of $\beta_{i}$ 250 relates to the total period of observation $l_{i}$ or the total number of observations at the active stations $251 \quad K_{i}$ in year $i$.

253 The following regression model is tested

$$
\beta_{i}=\boldsymbol{X} \boldsymbol{B}_{\beta i}+\boldsymbol{\varepsilon}_{\Sigma}
$$

254 where the following structure of $\boldsymbol{\Sigma}$ is assumed in the GLS model of $\boldsymbol{\beta}_{i}$

$$
\Sigma=\left[\begin{array}{cccc}
\sigma_{\varepsilon 1}^{2}+\sigma_{\delta}^{2} & 0 & \cdots & \\
0 & \sigma_{\varepsilon 2}^{2}+\sigma_{\delta}^{2} & & \\
\vdots & & \ddots & \\
& & & \sigma_{\varepsilon K}^{2}+\sigma_{\delta}^{2}
\end{array}\right]
$$

255 In the matrix $\sigma_{\varepsilon}$ represents the sampling uncertainty and $\sigma_{\delta}$ the residual uncertainty in the regression model. $\sigma_{\delta}$ is assumed to be unknown and is estimated along with the other variables in the regression model. $\sigma_{\varepsilon}$ is estimated as 


$$
\hat{\sigma}_{\varepsilon i}^{2}=\frac{c}{l_{i}} \quad \text { where } \quad c=\frac{1}{M} \sum_{i=1}^{M}\left(\frac{\sum_{s=1}^{K_{i}}\left(\beta_{i, s}-\overline{\beta_{i}}\right)^{2}}{K_{i, e f f}-1}\right)
$$

258 where $\bar{\beta}_{i}$ is the average over all sites.

260 The correlation between the stations, which was accounted for in the estimation of $\beta_{i}$, also affects 261 the variance of $\beta_{i}$ as the amount of independent information in the dataset is reduced. This is 262 accounted for by estimating the effective number of stations each year using [Madsen et al., 1994]

$$
K_{i, e f f}=K_{i}\left(1+\left(K_{i}-1\right) \overline{\rho_{i}}\right)^{-1}
$$

263 where $\bar{\rho}_{i}$ is the average correlation between stations active in the given year.

265 A description of $\sigma_{\varepsilon}$ for $\lambda_{i}$ and $\mu_{i}$ is given in Appendix A.2. For comparison, ordinary linear 266 regression (OLS) is also applied for the estimation of $\mathbf{B}_{\boldsymbol{\beta} i}$, where both sampling uncertainty and 267 spatial correlation are disregarded.

\subsection{SPATIO-TEMPORAL MODELS}

269 The concept of GLM solved by GEE was applied by Gregersen et al. [2013a] for the number of extreme events, $N$, which follows a Poisson distribution. GLM applies to all distributions within the exponential family and also allows for the use of a link function $(g)$ mapping the modelled variable $\left(\boldsymbol{\beta}_{i, s}\right)$ and the linear relation to the explanatory variable $(\boldsymbol{X})$ given by the regression parameters $\left(\boldsymbol{B}_{\eta}\right)$

$$
\boldsymbol{\eta}=\boldsymbol{X} \boldsymbol{B}_{\eta}+\boldsymbol{\varepsilon}_{\Sigma} \quad \text { where } \quad g\left(\boldsymbol{\beta}_{i, s}\right)=\boldsymbol{\eta}
$$

273 The link function can ensure that restrictions on the sample space are fulfilled, i.e. for $\beta_{i, s}, \lambda_{i, s}$ and $274 \mu_{i, s}$ only positive estimates are meaningful. The identity link, a log link and an inverse link are 275 among the commonly used functions [Faraway, 2006]. 
276 Several of the probability distributions from the PDS and GLS frameworks belong to the 277 exponential family, i.e. the Gaussian distribution, the Poisson distribution [Gregersen et al., 2013a] 278 and the Gamma distribution, of which the exponential distribution is a special case. The choice of 279 distribution in the GLM framework can be based on prior knowledge on the process generating the 280 data or from standard evaluations of the data and the model residuals. GLM is solved by maximum 281 likelihood procedures. The log-likehood is derived from the density function, where the link 282 function is included, before the values of $\boldsymbol{B}_{\boldsymbol{\eta}}$ that optimize the likelihood are estimated, either 283 directly or by an iteration scheme, Gregersen et al. [2013a].

With the GEE extension [Halekoh et al., 2006; Hardin and Hilbe, 2003] the GLM framework can account for spatial correlation between stations and a weight $\left(w_{i, s}\right)$ reflecting how many days during 287 a specific year a given station has been active. Gregersen et al. [2013a] showed how the correlation 288 matrix is included in the estimation equations for a Poisson model. The division of the observed 289 variance into sampling uncertainty and model uncertainty done by the GLS model cannot be 290 implemented in the same manner here, as $\sigma_{\varepsilon}$ in the marginal regional model is estimated from the 291 temporal variability and vice versa. GLM with the GEE extension is solved by maximum likelihood 292 procedures.

294 All calculations are performed using the statistical software R, using the packages 'geepack' 295 [Halekoh et al., 2006; Højsgaard et al., 2014], 'doBy’ [Højsgaard and Halekoh, 2014] and 'Imom' 296 [Hosking, 2014]. 
Rainfall series from 83 high-resolution tipping buckets are analyzed. The network was established in 1979 and has expanded since then, while a few stations are closed. All stations included in the present analysis have more than 10 years of measurements. When periods of rain gauge malfunction have been taken into account, the total dataset corresponds to 1881 station-years. The data resolution is one minute and $0.2 \mathrm{~mm}$. Rainfall durations of 10, 60, 180 and 1440 minutes are analyzed.

The network is operated by the Danish Water Pollution Committee and the Danish Meteorological Institute (DMI), who also conduct the quality-control. Data from this network has since 1998 been applied for estimation of design intensities for urban drainage design [Madsen et al., 2002], and the applied model has been updated twice [Madsen et al., 2009; In Review]. Analyzes of temporal variation of extreme rainfall by Gregersen et al. [2013a; 2013b] were also based on data from this network.

The most recent model for regional variation of extreme rainfall over Denmark applied two explanatory variables [Madsen et al., In Review] derived from Climate Grid Denmark (CGD). Here $\lambda$ varies with the Mean Annual Precipitation (MAP) [mm], while $\mu$ varies with the mean value of daily rainfall extremes $\left(\mu_{C G D}\right)[\mathrm{mm}]$. CGD is a gridded dataset of daily precipitation provided by DMI. It has a spatial resolution of $10 \times 10 \mathrm{~km}^{2}$ and covers the period 1989-2010 [Scharling, 2012]. The grid values are estimated from point measurements obtained from the regional network of daily precipitation stations owned by DMI using an inverse distance weighting method. The documented link between $\lambda$ and MAP is exploited in the present study; as we aim at having a constant $\lambda$ over space $z_{0}$ must vary with MAP. 
Gregersen et al. [2013a] tested several teleconnections as explanatory variables for the temporal variation in N, while Gregersen et al. [2014] concluded that the natural variability induced by these teleconnections can appear as short term temporal trends that last a few decades.. As the aim of the present study is to evaluate the influence of non-stationary data on a regional extreme value model, time is used as the only temporal explanatory variable. In this relation time is defined as the number of years since 1978. A year is defined as the calendar year January-December. The majority of extreme rainfall events occur in the period May-October [Gregersen et al., 2013b; Pedersen et al., 2012]. Therefore, with the use of the calendar year estimated extreme rainfall statistics are independent from year to year; a necessary assumption as mentioned in Section 2.2.3.

\section{RESULTS}

\subsection{SPATIO-TEMPORAL MODELS FOR $\beta$}

From type 2 censoring $P D S_{2}$ is defined as the fourth largest independent event at each site for each year. Subsequently, $\beta$ is estimated and the regional and temporal variability are evaluated by the two marginal models and the full spatio-temporal model. All models take into account the spatial dependence between the PDS series, which is estimated first.

\subsubsection{CORRELATION BETWEEN RAIN GAUGE STATIONS}

The spatial correlation structure, applied in the three models of $\beta$ is given in Figure 1. The shape of the correlogram depends on the rainfall duration. In general the correlation decreases with distance, but stations far away remains correlated. The shape of the curves corresponds well with the findings of Gregersen et al. [2013a] and Madsen et al. [In Review].

\subsubsection{MARGINAL REGIONAL MODEL FOR $\beta$}


Initial analyzes of the intercept model (not shown) confirm that $\widehat{\sigma}_{\delta}^{2}$ is positive for all durations. Hence regional variability exists, which potentially can be reduced by the introduction of explanatory variables. The following regression model is analyzed by GLS and for means of comparison by OLS:

$$
\beta_{s}=a+b \cdot M A P+\varepsilon_{\Sigma}
$$

The estimated model parameters are given in Table 1, while the observations and the modelled relation are shown in Figure 2 for all four durations. Accounting for spatial correlation and sampling uncertainty change the regression parameters and their uncertainty slightly (see Table 1). An influence of $M A P$ is suggested for very long rainfall (1440 min) durations.

As discussed in Madsen et al. [In Review], it is expected that the variability over time, when not accounted for, is introducing an additional uncertainty in the regional model. The length of observation period differs between stations. An effect of this can be seen from Figure 2 where stations, which have been active approximately during the entire period from 1979 to 2012, are marked with black. The variability in this subset of stations is remarkably lower than the variability of the entire sample. In Section 4.1.4, it is shown that the spatio-tempor al model accounts for this.

\subsubsection{MARGINAL TEMPORAL MODEL FOR $\beta$}

For $\beta$ the spatial correlation is relatively high, also for sites separated by long distances (see Section 4.1.1). This has a substantial effect on the sampling uncertainty, because $K_{i, \text { eff, }}$, despite the large number of stations in the network, is very small, s ee Eq.(15). Still, initial analyzes of the intercept model (not shown) confirm that $\bar{\sigma}_{\delta}^{2}$ is positive for 10 and 60 minutes and is greatly reduced by the introduction of temporal regressors. Gregersen [2015] showed that when $\lambda$ is 
analyzed in a similar manner $\hat{\sigma}_{\delta}^{2}$ is positive for all durations. Therefore the analysis is continued for

366 all durations and the following regression model is analyzed by GLS:

$$
\beta_{i}=a+c \cdot \text { time }+\varepsilon_{\Sigma}
$$

367 Again, parameter estimates from OLS regression are also assessed. Estimated model parameters are given in Table 2, while the observations and the modelled relations are shown in Figure 3 for all four durations. For all rainfall durations $\beta_{i}$ increases over time. A comparison between OLS and GLS (not included) shows that the standard errors on the regression slopes for 10 and 60 minutes increase slightly when the sampling uncertainty is taken into account. Besides that the other parameter estimates are almost identical for the two methods.

\subsubsection{THE FULL SPATIAL AND TEMPORAL MODEL FOR $\beta$}

374 The two marginal models show variability in both domains and thereby a need for the formulation 375 of a spatio-temporal model. The following regression model is analyzed by GLM-GEE

$$
\eta_{i, s}=a+b \cdot M A P+c \cdot \text { time }+\varepsilon_{\Sigma} \quad \text { where } \quad g\left(\beta_{i, s}\right)=\eta_{i, s}
$$

It must be evaluated which underlying probability distribution is best suited to describe $\beta_{i, s}$. A histogram combined with a kernel-approximation of the density function shows no large deviations from a Gaussian distribution, see Figure 4a. Furthermore, different distributions and link functions were tested in the GLM-GEE model. It was found that the parameter estimates varied little and that the residuals showed approximately the same behavior independent of the choice of model, see Figure $4 \mathrm{~b}$ and Figure 4c. For the convenience of direct comparison with the parameter estimates from the two marginal GLS models, the subsequent analysis is based on a GLM-GEE model with a Gaussian distribution and an identity link function. 
Table 3 shows the results for all four rainfall durations using the most complex GLM-GEE model with both weights and correlation. It has been evaluated how the assumption on the structure of the residuals (weights and correlation) affects the parameter estimates and their significance (not shown). The conclusion depends on the rainfall durations, but in general the variation of the parameter estimates and their significance are not substantially different from the variation between the OLS and the GLS estimates in the marginal models.

For all durations the full model with weights and correlation reduces the parameter uncertainty on $b$ compared to the marginal regional GLS model, see Table 3. This leads to a significant correlation to $M A P$ for all durations but 60 minutes. The estimate of $b$ has decreased for $10 \mathrm{~min}$, but increased for 180 and 1440 minutes. This corresponds well to the behaviour reported by Madsen et al. [In Review]. All in all it is confirmed that when the assumption of stationarity is not fulfilled the overall model uncertainty increases with the available information. The spatio-temporal model solves this issue. The estimates of $c$ are also slightly different from the estimates of the marginal temporal model as an effect of the variability explained by $M A P$ and the covariance between the 400 parameter estimates.

\subsection{TYPE 1 CENSORING APPLYING A SPATIO-TEMPORAL THRESHOLD}

The spatio-temporal model of $\beta$ is applied as a deterministic model for $z_{0}$ to define a new PDS from $\boldsymbol{Y}$ using type 1 censoring $\left(P D S_{1}\right)$. When $z_{0}$ varies in time and space, $\lambda$ must not exhibit any 404 significant variations over time and space. For a duration of 60 minutes a regression to $M A P$ is 405 included even though it is non-significant.

407 From $P D S_{1}$ the GPD parameters from Eq.(6) are estimated, and their variation over time and space 408 is assessed including the spatial correlation structure. 


\subsubsection{CORRELATION BETWEEN RAIN GAUGE STATIONS}

The spatial correlation structure for $\lambda$ and $\mu$ is given in Figure 5 and Figure 6, respectively. The shape of the correlogram depends on the rainfall duration. In general, the correlation decreases with distance, and this happens quickly for $\mu$, while for $\lambda$ stations far away remain correlated. A comparison with the findings by Madsen et al. [In Review] (not shown) indicates that when a nonstationary threshold is applied the correlation decreases slightly.

\subsubsection{VARIATIONS OF $\lambda$ OVER TIME AND SPACE}

The two following marginal regression models are analyzed

$$
\begin{aligned}
& \lambda_{s}=a+b \cdot M A P+\varepsilon_{\Sigma} \\
& \lambda_{i}=a+c \cdot t i m e+\varepsilon_{\Sigma}
\end{aligned}
$$

to test that the application of the non-stationary and regional $z_{0}$ leads to constant $\lambda$ over time and space. This is confirmed. Furthermore, the variability of all data points and a subset of data points representing the stations with long records (black dots) are comparable, see Figure 7. This is not the case when the temporal variability is not accounted for, see Figure 2. Station outliers are observed for all durations. Two stations from suburbs west of Copenhagen recur as outliers. As they both are approved by the quality control, they are retained in the dataset. One of the stations was closed in 1995.

The following regression model is analyzed by GLM-GEE to estimate the constant $\lambda$ and the uncertainty on the estimate:

$$
\eta_{i, s}=a+\operatorname{offset}\left(\log \left(l_{i, s}\right)\right)+\varepsilon_{\Sigma} \quad \text { where } \quad \log \left(N_{i, s}\right)=\eta_{i, s}
$$

$N_{i, s}$ is assumed to follow a Poisson distribution, while the variability of $\lambda_{i, s}$ can be modelled by including the observation period in the model as an offset. A Poisson model with a log-link function is applied following the approach by Gregersen et al. [2013a]. The results are given in Table 4 . 
429 The scale of the Poisson distribution is reported to evaluate if $N_{i, s}$ shows overdispersion; values 430 close to one indicate that this is not the case. The results are applied for estimation of design 431 intensities in Section 4.3.

\subsubsection{VARIATIONS OF $\mu$ OVER TIME AND SPACE}

433 are analyzed

$$
\begin{gathered}
\mu_{s}=a+b \cdot \mu_{C G D}+\varepsilon_{\Sigma} \\
\mu_{i}=a+c \cdot \text { time }+\varepsilon_{\Sigma}
\end{gathered}
$$

436 The regression between $\mu$ and time is positive, see Figure 8, and significant for all durations but 4371440 minutes, see Table 5. The regression between $\mu$ and $\mu_{C G D}$ is positive, see Figure 9 , and 438 significant on a 10\% confidence level for 10, 180 and 1440 minutes, see Table 5. However, residual 439 following model and analyzed by GLM-GEE

$$
\eta_{i, s}=a+b \cdot \mu_{C G D}+c \cdot \text { time }+\varepsilon_{\Sigma} \quad \text { where } \quad g\left(\mu_{i, s}\right)=\eta_{i, s}
$$

443 A histogram of $\mu_{i, s}$ shows a distribution with a positive skew, which is suggesting the use of a 444 Gamma distribution in the GLM-GEE, see Figure 10. A Gamma model is also suitable if the residual analysis suggests that the increase of the variance is captured best by the inverse link, see variance of the residuals increases with the mean. As potential link functions for the Gamma model, a $\log$ link and an inverse link are considered. Evaluations show that the significance of the regression parameters are almost identical for the two different link functions (not shown), but Figure 10. Therefore, the inverse link is applied. The estimated model parameters are given in Table 
5. These show a difference between the significance of the regression coefficients in the marginal 451 models and the full model. The reason is that the underlying model assumptions differ as the gamma model can account for an increase of the variance. This probably leads to the found difference in significance of $\mu_{C G D}$ for 10 and 180 minutes.

454 455 456 457 458 459 460 461 events is suggested

$$
z_{T, i, s}=z_{0, i, s}+\mu_{i, s} \frac{1+\kappa}{\kappa}\left[1-\left(\frac{1}{\lambda T}\right)^{\kappa}\right]
$$
$z_{0 i, S}$ is fixed in the applied PDS procedure and hence by definition not uncertain. All other 464 are found significant in the full model. By use of Eq.(26) the 10-year event $\left(z_{10 i, s}\right)$ is predicted for 465 two locations in Denmark and compared to the results from Madsen et al. [In Review], see Table 7. 466 The uncertainty on $z_{10 i, s}$ is approximated by a second order Taylor expansion of Eq.(26) [Madsen et 467 al., 2002].

469 The temporal development of the 10-year event is strongest for 10, 60 and 180 minutes, where both 470

\subsubsection{VARIATIONS OF $L_{C V}$ OVER TIME AND SPACE}

$L_{c v}$ exhibits no apparent variation over space and time (not shown). Estimation of the heterogeneity measure from Hosking and Wallis [1993] confirms that the parameter can be regarded as homogenous. $L_{c v}$ is estimated following the method from Madsen et al. [2002], and results are given in Table 6.

\subsection{ESTIMATION OF DESIGN INTENSITIES}

Based on the results from the preceding sections the following model for the estimation of T-year parameters estimated from $P D S_{1}$ are predicted from the regional and temporal covariates, if these $\lambda$ and $\mu$ has a non-stationary component. For these three durations the estimate from Madsen et al. 
471 [In Review] lies in between the two years for which predictions are made (see Table 7). This 472 corresponds well with the data that the model by Madsen et al. [In Review] is built on. For 1440 473 min the variability is strongest in the regional domain as both $\lambda$ and $\mu$ has a regional component. A 474 small temporal variability is seen due to the temporal development in $\lambda$. Comparing the estimated 475 uncertainties on the 10-year events, with the results from Madsen et al. [In Review] it is seen, that 476 the proposed regional and non-stationary model for PDS successfully eliminates the uncertainty 477 introduced when the assumption of stationarity is not fulfilled.

\section{DISCUSSION}

The identified model is primarily used for explorative purposes. Over the last 15 years the urban drainage engineering community has experienced increases of recommended design intensities of extreme precipitation of the 'present' (i.e. 'stationary') climate that by far exceeds the anticipated changes due to emissions of greenhouse gasses in any of the future scenarios foreseen by the climate change communities. The purpose of the model has been to validate that this process has taken place and to separate the process into a regional and a temporal component. Future work will focus on separating the temporal component into processes that can be validated and predicted, thereby distinguishing between observed dynamics in the past, present, and future, and anticipated climatic changes due to emissions of greenhouse gasses.

Using the identified model it is in principle possible to obtain design values for infrastructure by 490 extrapolating into the future and consider e.g. the maximum design values over the expected 491 technical lifetime and using that in the design process. Procedures for making such projections 492 (although for different variables than precipitation) are described in e.g. Larsen et al. [2003] and Arnbjerg-Nielsen [2011]. However, as pointed out in a commentary by Montanari and 
494 Koutsoyiannis [2014] the practical application of statistical models with a time-dependent 495 component can be questionable, which is why process-based models are preferable. This study has 496 not addressed the physical processes which could lie behind the temporal variation. Several studies 497 indicate that large scale climatic variables may influence extreme rainfall [e.g. Sun et al., 2014; 498 Willems 2013], but even when the large scale physical drivers are known, several challenges still 499 remain; first to predict their future states, secondly to select which state to apply when choosing the 500 design intensity. Hence, the present study demonstrates the non-stationary model using time as 501 covariate. Since all model applications are uncertain outside the range of the input variables we do 502 not recommend to use the identified model in its present form for estimating design intensities for 503 the future.

As pointed out by Willems [2013] and Gregersen et al. [2014] there may be some cyclical processes occurring with low frequency that, once understood, can serve as a more suitable co-variate in the model. This would enable projections into the future that are more trust-worthy if future states of these co-variates can be obtained. If climate drivers replace the variable time, this will have an 509 effect on the model residuals and the estimated uncertainty on the design intensities. This potential 510 reduction in uncertainty is, based on earlier work using teleconnections, assumed to be minor in 511 comparison to the difference between including and not including a temporal variable [Gregersen et al., 2013a].

\section{CONCLUSION}

514 In conclusion, the suggested GLM-GEE procedure is shown to be highly qualified for modelling spatio-temporal variability in $\beta, \lambda$ and $\mu$ and thereby for the construction of a non-stationary regional extreme value model, which can be used for the estimation of urban design rainfall. 
518 The dataset is first assessed by type 2 PDS censoring to find a suitable model for the threshold. The model is subsequently used in type 1 PDS censoring to ensure that the occurrences of extreme events are identically distributed over the sample period. These PDS are analyzed for a temporal 521 and regional development in the mean exceedances and the shape parameter. The GLM-GEE framework can include a spatial correlation between the measurements and a weight reflecting a possible difference in the observation period. However, it is not possible to include the sampling uncertainty of the observation directly. If the magnitude of the sampling uncertainty is equal to the total variability of the data, there is no reason to search for regional or temporal explanatory variables. It is therefore recommended to assess the marginal development in space and time, and the magnitude of sampling uncertainty in both domains before the full spatio-temporal model is applied. Thereby, model overfitting and underestimation of uncertainty are avoided. A GLS framework is well suited for evaluation of the marginal models.

Rainfall duration of 10, 60, 180 and 1440 minutes were analyzed. For $\beta$, a spatio-temporal model is suggested, applying the Mean Annual Precipitation and time as the explanatory variables in the regional and temporal domain, respectively. This threshold model ensures a constant $\lambda$. A significant temporal increase in the mean of the extreme exceedences was found for $10,60,180$ minutes, while for 1440 minutes a significant regional variability was found. No significant temporal or regional variability of the shape parameter was found, and hence a regionally constant estimate was applied.

Westra and Sisson [2011] and Roth et al. [2012] accessed the effect of spatial correlation on the 539 identification of temporal trends by different methods. A comparison of methods is highly relevant. The next step is to evaluate the differences and similarities of the proposed model and the methods 
541 of Ghosh and Mallick [2011], Roth et al. [2012] and Thibaud et al. [2013], in terms of spatial 542 correlation, significance of spatial and temporal variables, and prediction of urban design 543 intensities.

\section{Acknowledgements}

546 This work was carried out with the support of the Danish Strategic Research Council as part of the 547 project 'Centre for Regional Change in the Earth System', contract no. 09-066868 and from The 548 Foundation for Development of Technology in the Danish Water Sector, contract no. 7492-2012. 549 The authors are also grateful to Danish Water Pollution Committee for providing the data. The rain 550 gauge series are not freely available for download; access can be granted for research purposes. The 551 authors can provide both R-scripts and processed data-series for the reproduction of the published 552 results. 


\section{REFERENCES}

Arnbjerg-Nielsen K. (2011). Past, present, and future design of urban drainage systems with focus on Danish experiences. Water Science and Technology, 63(3), 527-535. DOI: $10.2166 /$ wst.2011.253

Aryal, S. K., B. C. Bates, E. P. Campbell, Y. Li, M. J. Palmer and N. R. Viney (2009). Characterizing and modeling temporal and spatial trends in rainfall extremes. Journal of Hydrometeorology. 10(1), 241-253. DOI: 10.1175/2008JHM1007.1

Coles, S. (2001). An introduction to statistical modeling of extreme values. Springer. London, UK.

Cooley, D., D. Nychka and P. Naveau (2007). Bayesian spatial modeling of extreme precipitation return levels. Journal of the American Statistical Association. 102(479), 824-840.

Dyrrdal, A. V., Lenkoski, A., Thorarinsdottir, T. L., and Stordal, F. (2014). Bayesian hierarchical modeling of extreme hourly precipitation in Norway. Environmetrics. DOI: 10.1002/env.2301

Faraway, J.J. (2006). Extending the linear model with R: Generalized linear, mixed effects and nonparametric regression models. Chapman and Hall/CRC. Boca Raton, Florida, U.S.

Fowler, H. J. and C. G. Kilsby (2003). A regional frequency analysis of United Kingdom extreme rainfall from 1961 to 2000. International Journal of Climatology. 23(11), 1313-1334. DOI: $10.1002 /$ joc. 943

Frich, P., S. Rosenørn, H. Madsen and Jensen, J.J. (1997). Observed precipitation in Denmark, 1961-1990. Technical report 97-8. Danish Meteorological Institute, Ministry of Transport. Copenhagen, Denmark.

Ghosh, S. and B. K. Mallick (2011). A hierarchical Bayesian spatio-temporal model for extreme precipitation events. Environmetrics. 22(2), 192-204. DOI: 10.1002/env.1043

Gregersen, I. B., H. Madsen, D. Rosbjerg and K. Arnbjerg-Nielsen (2013a). A spatial and nonstationary model for the frequency of extreme rainfall events. Water Resources Research. 49(1), 127-136.

Gregersen, I. B., H. J. D. Sørup, H. Madsen, D. Rosbjerg, P. S. Mikkelsen and K. Arnbjerg-Nielsen, (2013b). Assessing future climatic changes of rainfall extremes at small spatio-temporal scales. Climatic Change. 118(3-4), 783-797. DOI: 10.1007/s10584-012-0669-0

Gregersen, I. B., H. Madsen, D. Rosbjerg and K. Arnbjerg-Nielsen (2014). Long term variations of extreme rainfall in Denmark and southern Sweden. Climate Dynamics. 44(11-12), 3155-3169. DOI: $10.1007 / \mathrm{s} 00382-014-2276-4$ 
Gregersen, I. B. (2015). Past, present and future variations of extreme rainfall in Denmark, Ph.D. Thesis. Department of Environmental Engineering, Technical University of Denmark, Kgs. Lyngby, Denmark.

Haddad, K., A. Rahman and Green, J. (2011). Design rainfall estimation in Australia: a case study using L moments and Generalized Least Squares Regression. Stochastic Environmental Research and Risk Assessment. 25(6), 815-825. DOI: 10.1007/s00477-010-0443-7

Halekoh, U., S. Hojsgaard and Yan, J. (2006). The R Package geepack for Generalized Estimating Equations. Journal of Statistical Software. 15(2), 1-11.

Hardin, J.W. and J.M. Hilbe (2003). Generalized estimating equations. Chapman \& Hall/CRC. Boca Raton, Florida, U.S.

Heaton, M. J., M. Katzfuss, S. Ramachandar, K. Pedings, E. Gilleland, E. Mannshardt-Shamseldin and R. L. Smith (2011). Spatio-temporal models for large-scale indicators of extreme weather. Environmetrics. 22(3), 294-303. DOI: 10.1002/env.1050

Hosking, J. R. M. (1990). L-moments: analysis and estimation of distributions using linear combinations of order statistics. Journal of the Royal Statistical Society. Series B (Methodological). 52(1), 105-124.

Hosking, J. R. M. and J. R. Wallis (1993). Some Statistics Useful in Regional Frequency-Analysis. Water Resources Research. 29(2), 271-281.

Hosking, J. R. M. (2014). Package 'Imom', February 20 2015, version 2.5. Available from: http://cran.r-project.org/web/packages/lmom/lmom.pdf . Assessed: July 2016.

Højsgaard, S and U. Halekoh (2014). Package ‘doBy', March 31 2016, version 4.5-15. Available from: http://cran.r-project.org/web/packages/doBy/doBy.pdf . Assessed: July 2016.

Højsgaard, S, U. Halekoh and J. Yan (2014). Package 'geepack', July 2016, version 1.2-0.2 Available from: http://cran.r-project.org/web/packages/geepack/geepack.pdf . Assessed: July 2016.

Kyselý, J., J. Picek and R. Beranova (2010). Estimating extremes in climate change simulations using the peaks-over-threshold method with a non-stationary threshold. Global and Planetary Change. 72(1-2), 55-68. DOI: 10.1016/j.gloplacha.2010.03.006

Larsen, O.D., Moelgaard, C. and Kampmann, J. (2003). Flooding of the Copenhagen Metro, Denmark. Structural Engineering International, 13(4), 231-234.

Madsen, H., D. Rosbjerg and P. Harremoës (1994). PDS-modelling and regional Bayesian estimation of extreme rainfalls, Nordic Hydrology. 25(4), 279-300. 
Madsen, H. and D. Rosbjerg (1997). Generalized least squares and empirical Bayes estimation in regional partial duration series index-flood modeling. Water Resources Research. 33(4), 771781.

Madsen, H., P. S. Mikkelsen, D. Rosbjerg and P. Harremoes (2002). Regional estimation of rainfall intensity-duration-frequency curves using generalized least squares regression of partial duration series statistics. Water Resources Research. 38(11).

Madsen, H., K. Arnbjerg-Nielsen and P. S. Mikkelsen (2009). Update of regional intensityduration-frequency curves in Denmark: Tendency towards increased storm intensities. Atmospheric Research. 92(3), 343-349. DOI: 10.1016/j.atmosres.2009.01.013

Madsen, H., D. Lawrence, M. Lang, M. Martinkova, T.R. Kjeldsen (2014). Review of trend analysis and climate change projections of extreme precipitations and floods in Europe. Journal of Hydrology. 519(PD), 3634-3650. DOI: 10.1016/j.jhydrol.2014.11.003

Madsen, H., I. B. Gregersen, D. Rosbjerg and K. Arnbjerg-Nielsen (In Review). Regional frequency analysis of short duration rainfall extremes using gridded daily rainfall data as co-variate. Submitted to Water Science and Technology.

Mikkelsen, P. S., H. Madsen, D. Rosbjerg, and P. Harremoes (1996). Properties of extreme point rainfall .3. Identification of spatial inter-site correlation structure. Atmospheric Research. 40(1), 77-98. DOI: 10.1016/0169-8095(95)00026-7

Mikkelsen, P. S., P. Harremoes and D. Rosbjerg (1995). Properties of extreme point rainfall .2. Parametric data interpretation and regional uncertainty assessment. Atmospheric Research. 37(1995), 287-304. DOI: 10.1016/0169-8095(94)00054-H

Min, S. K., X. Zhang, F. W. Zwiers and Hegerl, G. C. (2011). Human contribution to more-intense precipitation extremes. Nature. 470(7334), 376-379. DOI: 10.1038/nature09763

Montanari, A. and D. Koutsoyiannis, (2014). Modelling and mitigating natural hazards: Stationarity is immortal!. Water Resources Research. 50(12), 9748-9756. DOI: 10.1002/2014WR016092

Pedersen, A. N., P. S. Mikkelsen and K. Arnbjerg-Nielsen (2012). Climate change-induced impacts on urban flood risk influenced by concurrent hazards. Journal of Flood Risk Management. 5(3), 203-214. DOI: 10.1111/j.1753-318x.2012.01139.x

Renard, B. (2011). A Bayesian hierarchical approach to regional frequency analysis. Water Resources Research.47(11).

Rosbjerg, D., H. Madsen, and P. F. Rasmussen (1992). Prediction in Partial Duration Series with generalized Pareto distributed exceedances. Water Resources Research. 28(11), 3001-3010.

Roth, M., T. Buishand, G. Jongbloed, A. Tank and J. van Zanten (2012). A regional peaks-overthreshold model in a nonstationary climate. Water Resources Research. 48(11). 
Scharling, M. (2012). Climate Grid Denmark - Dataset of use in research and education - Daily and monthly values 1989-2010. Technical report 12-10. Danish Meteorological Institute, Ministry of Climate and Energy. Copenhagen, Denmark.

Stedinger, J. R. and G. D. Tasker (1985). Regional Hydrologic Analysis .1. Ordinary, weighted, and generalized least-squares compared. Water Resources Research. 21(9), 1421-1432.

Sun, X., M. Thyer, B. Renard and M. Lang (2014). A general regional frequency analysis framework for quantifying local-scale climate effects: A case study of ENSO effects on Southeast Queensland rainfall. Journal of Hydrology. 512(2014), 6586-6601. DOI: 10.1016/j.jhydrol.2014.02.025

Sun, X., U. Lall, B. Merz and N.V. Dung (2015). Hierarchical Bayesian clustering for nonstationary flood frequency analysis: Application to trends of annual maximum flow in Germany. Water Resources Research. 51(8), 6586-6601.

Thibaud, E., R. Mutzner and A. Davison (2013). Threshold modeling of extreme spatial rainfall. Water Resources Research. 49(8), 4633-4644.

Wallis, J., M. Schaefer, B. Barker and G. Taylor (2007). Regional precipitation-frequency analysis and spatial mapping for 24-hour and 2-hour durations for Washington State. Hydrology and Earth System Sciences. 11(1), 415-442.

Westra, S. and S. A. Sisson (2011). Detection of non-stationarity in precipitation extremes using a max-stable process model. Journal of Hydrology. 406(1-2), 119-128. DOI: 10.1016/j.jhydrol.2011.06.014

Westra, S., L. V. Alexander and F. W. Zwiers (2013). Global increasing trends in annual maximum daily precipitation. Journal of Climate. 26(11), 3904-3918. DOI: 10.1175/JCLI-D-12-00502.1

Willems, P. (2013) Multidecadal oscillatory behaviour of rainfall extremes in Europe. Climatic Change. 120(4), 931-944. DOI: 10.1007/s10584-013-0837-x

\section{APPENDICES}

\section{A.1 SAMPLING UNCERTAINTY FOR THE MARGINAL REGIONAL MODEL}

The applied procedure for estimation of the sample uncertainty on $\beta_{s}, \lambda_{s}, \mu_{s}$ and $L_{C V s}$ are reviewed below, starting with $\beta_{s}$. Unless specifically stated the procedures follow Madsen and Rosbjerg [1997]. 
681 For any of the of the four GPD parameters the GLS procedure requires, that the at-site estimate of 682 the sampling uncertainty $\left(\hat{\sigma}_{\varepsilon S}\right)$ is nearly independent of the estimated parameter $\left(\hat{\theta}_{S}\right)$ [Madsen and 683 Rosbjerg, 1997]. Madsen and Rosbjerg [1997] and Madsen et al. [2002] therefore applied an estimation procedure based on sample estimates of the population parameters.

685

A given site $s$ has $M_{s}$ observations of $\beta$; one for each year where the station has been active. On this basis the mean and variance of $\beta$ are estimated for each site, and subsequently for the entire 688 population by averaging over all $K$ sites. A site specific estimation of the sampling uncertainty is obtained by accounting for the actual observation period at the site, $l_{s}$ :

$$
\hat{\sigma}_{\varepsilon s}^{2}=\frac{c}{l_{s}} \quad \text { where } \quad c=\frac{1}{K} \sum_{s=1}^{K}\left(\frac{\sum_{i=1}^{M_{s}}\left(\beta_{i, s}-\overline{\beta_{0 s}}\right)^{2}}{M_{s}-1}\right)
$$

690 where $\overline{\beta_{s}}$ is the average over all sites.

691

The sampling uncertainty of $\lambda_{s}$ is estimated from a procedure identical to the one described for $\beta_{s}$. In Madsen and Rosbjerg [1997] and Madsen et al. [2002] it is utilized that $\lambda_{s}$ is the rate parameter of the Poisson distribution and hence the variance equals the mean. To ensure consistency between the sampling uncertainty estimates in the marginal regional and temporal model the approach from equation $1 \mathrm{~A}$ is preferred. In the marginal temporal model correlation between stations is accounted for in the estimation of the variance. This procedure cannot be applied if the variance is assumed equal to the mean.

The sampling uncertainty of $\mu_{s}$ is estimated from a procedure similar to the one described for $\beta_{s}$. A given site $s$ has $n_{s}$ observations of extreme rainfall with intensity $y . n_{s}$ is indirectly related to how many years the station has been active. The mean and variance are estimated for each site, and 
subsequently for the entire population by averaging over all $K$ sites. A site specific estimation of the sampling uncertainty is obtained by accounting for the number of observations at the site, $n_{s}$ :

$$
\hat{\sigma}_{\varepsilon s}^{2}=\frac{c}{n_{s}} \quad \text { where } \quad c=\frac{1}{K} \sum_{s=1}^{K}\left(\frac{\sum_{j=1}^{n_{s}}\left(y_{j}-\mu_{s}\right)^{2}}{n_{s}-1}\right)
$$

705

706

707

708

709

710

711

712

713

714

where $\mu_{s}$ is the average over all sites.

For higher moments the estimation of the sampling uncertainty cannot be based on the population parameters if the independence criteria should be fulfilled. Simulations are therefore required. A four parameter kappa distribution is suitable for this purpose because of its flexibility [Madsen et al., 2002].

The sampling uncertainty of $L_{C V s}$ is estimated from Monto Carlo simulation using the kappa distribution with parameters estimated from regional estimates of the first four L-moments. In total 500 series with $\overline{n_{s}}$ observations are generated from this distribution, and applied for estimation of $\operatorname{Var}\left(L_{c v}\right)_{m c}$. Here $\overline{n_{s}}$ is the average number of events over all sites. A site specific estimation of the sample uncertainty is obtained accounting for the ratio between $\overline{n_{s}}$ and the actual number of observations at the site, $n_{s}$ :

$$
\hat{\sigma}_{\varepsilon s}^{2}=\frac{c}{n_{s}} \quad \text { where } \quad c=\operatorname{Var}\left(L_{c v}\right)_{m c} \cdot \overline{n_{s}}
$$

\section{A.2 SAMPLING UNCERTAINTY FOR THE MARGINAL TEMPORAL MODEL}

The applied procedure for estimation of the sampling uncertainty of $\beta_{i}, \lambda_{i}$ and $\mu_{i}$ is reviewed below, starting with $\beta_{i}$. 

between stations by dividing the sum of squared differences with $K_{i, e f f}$, which is estimated from:

$$
K_{i, e f f}=K_{i}\left(1+\left(K_{i}-1\right) \overline{\rho_{i}}\right)^{-1}
$$
732 where $\overline{\rho_{i}}$ is the average correlation between stations active in the given year. The mean and

The marginal temporal GLS model is similar to the marginal regional GLS model, just averaging over the regional domain instead. The considerations regarding appropriate estimators of the sampling uncertainty given for the regional GLS model therefore applies. With the important difference that the estimate of sampling uncertainty is affected by the correlation between sites, which reduces the amount of information in the data set and increases the sample estimate of the population variance.

For $\beta$ a given year $i$ has $K_{i}$ observations of $\beta$, one for each station active that year. On this basis the mean and variance are estimated for each year. The variance is corrected for the correlation variance are estimated by averaging over all $M$ years. A site specific estimation of the sampling uncertainty is obtained by accounting for the actual number of active stations in the given year and their breakdown periods, i.e. the number of station years $l_{i}$ :

$$
\tilde{\sigma}_{\varepsilon i}^{2}=\frac{c}{l_{i}} \quad \text { where } \quad c=\frac{1}{M} \sum_{i=1}^{M}\left(\frac{\sum_{s=1}^{K_{i}}\left(\beta_{i, s}-\overline{\beta_{0 i}}\right)^{2}}{K_{i, e f f}-1}\right)
$$

The sampling uncertainty of $\lambda_{i}$ is estimated from a procedure identical to the one described for $\beta_{i}$.

The sampling uncertainty of $\mu_{i}$ is also estimated from a procedure similar to the one described for $\beta_{i}$. A given year $i$ has $n_{i}$ observations of extreme rainfall with intensity $y$. On this basis the mean and variance are estimated for each year. The variance must again be corrected for the correlation between stations. However, as one site often has more than one observation and at-site observations are uncorrelated $n_{i, e f f}$ is estimated as: 


$$
n_{i, e f f}=\overline{n_{i}} K_{e f f}
$$

743 where $\bar{\rho}_{i}$ is the average correlation between stations active in the given year and $K_{i, e f f}$ is given by 744 (4A). The mean and variance are estimated by averaging over all $M$ years. A site specific estimation 745 of the sampling uncertainty is obtained by accounting for the actual number of active observations 746 that year:

$$
\widehat{\sigma}_{\varepsilon i}^{2}=\frac{c}{n_{i}} \quad \text { where } \quad c=\frac{1}{M} \sum_{i=1}^{M}\left(\frac{\sum_{j=1}^{n_{s}}\left(y_{j}-\mu_{i}\right)^{2}}{n_{i, e f f}-1}\right)
$$


All figures with caption. Figure 

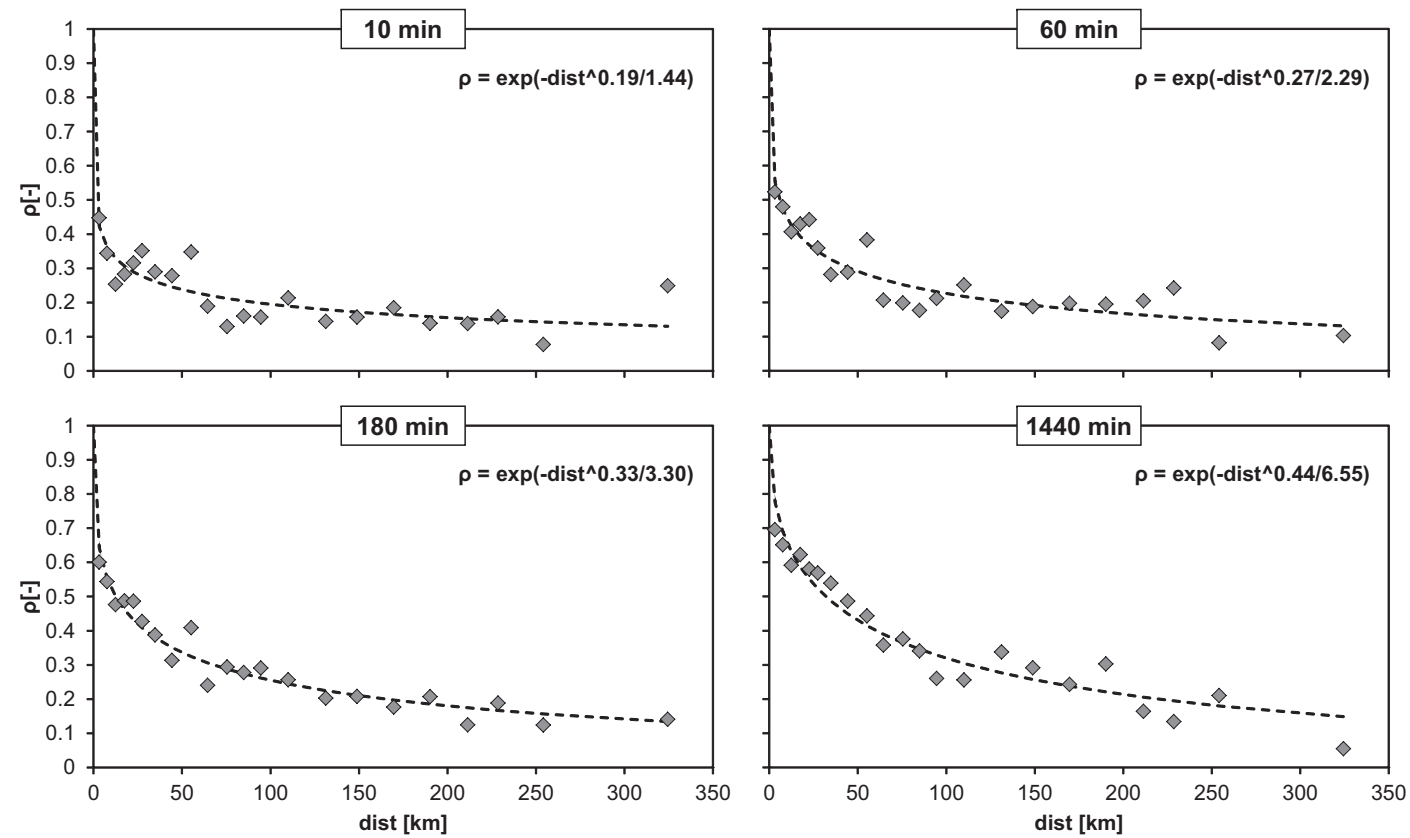

Figure 1. The correlogram for the spatial variation of $z_{0}$ for the four durations. Dots represent the observed correlation averaged in selected bins, the black line represents the fitted exponential model given in the top left of each graph. 

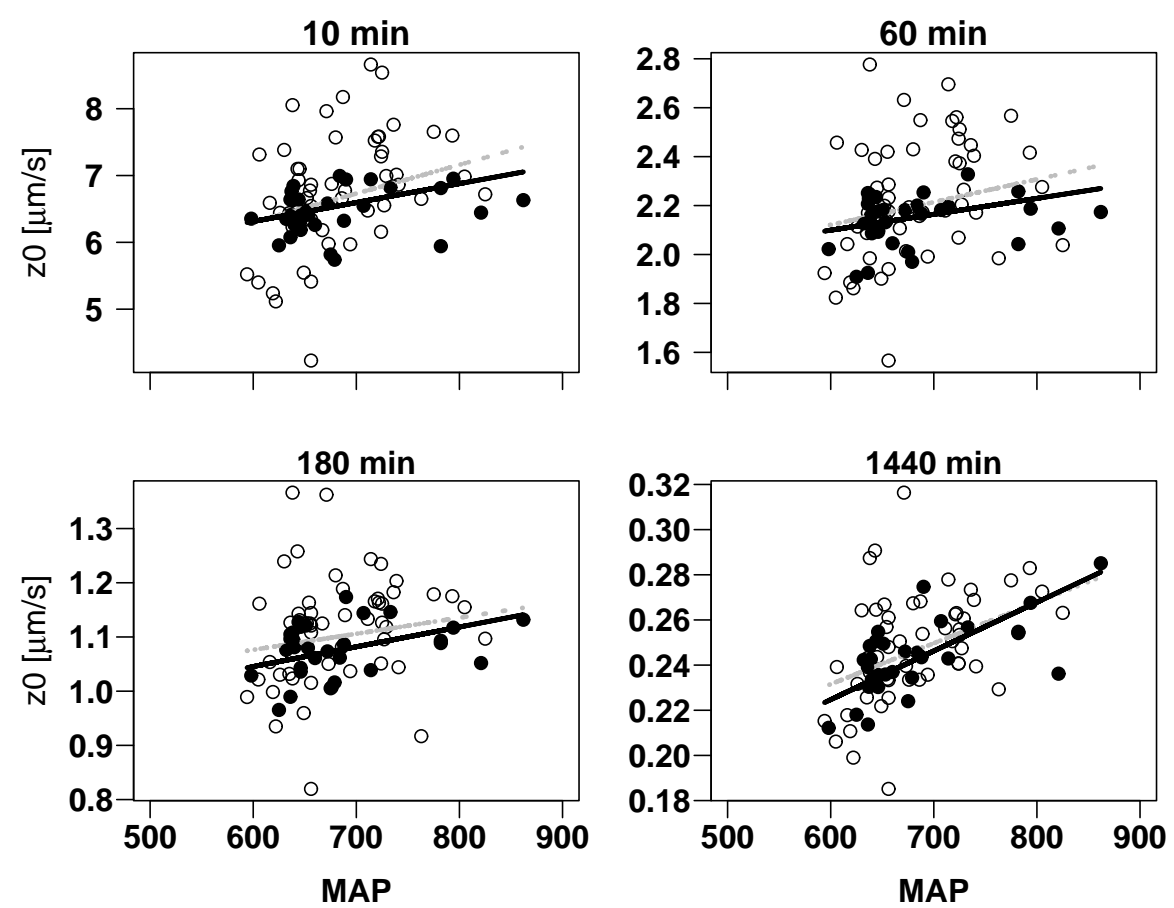

Figure 2. The OLS and GLS regression, in grey and black, respectively, showing the variation of $z_{0}$ as a function of MAP. The marked $z_{0}$ values are from stations with more than 30 years of observation and thereby have a high weight in the GLS model. 

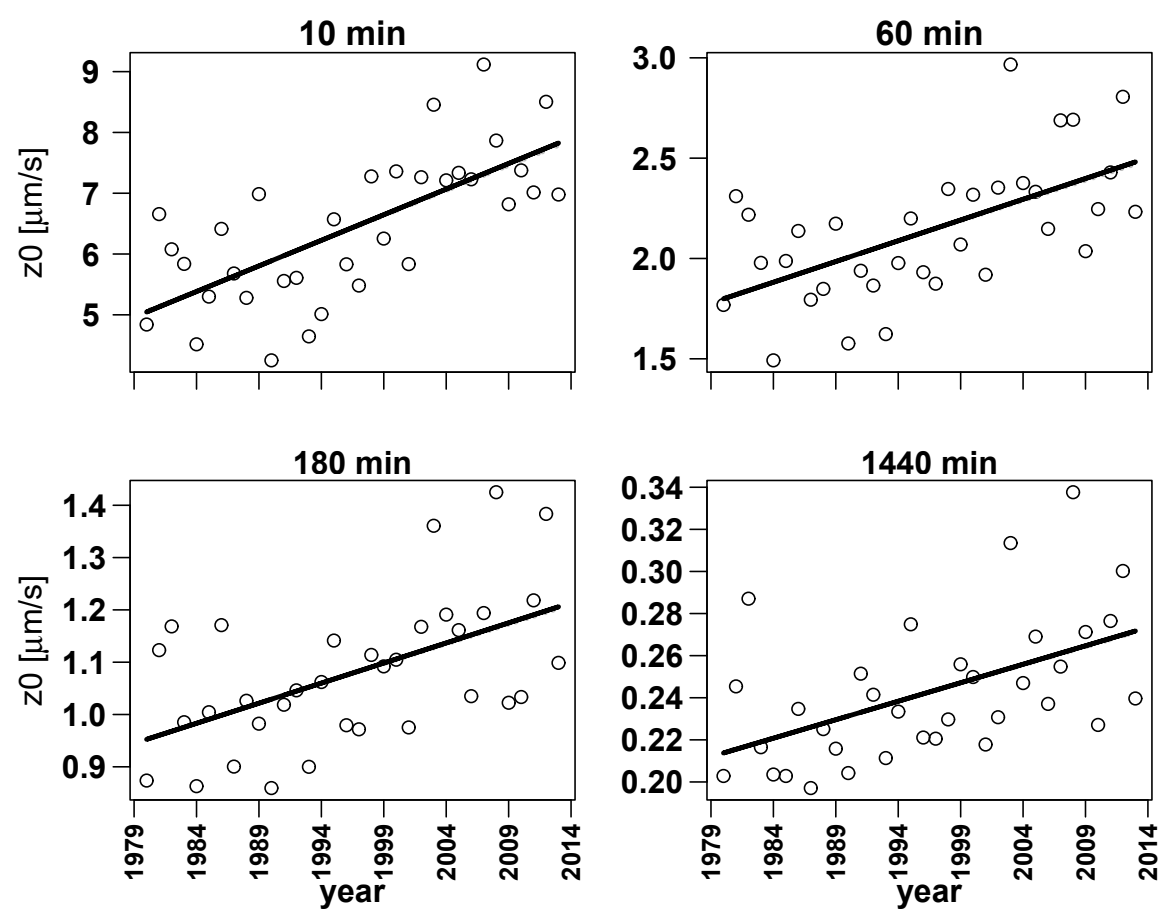

Figure 3. The OLS and GLS regression (which are identical), showing the variation of $z_{0}$ as a function of time.

a) Histogram of $z 0$

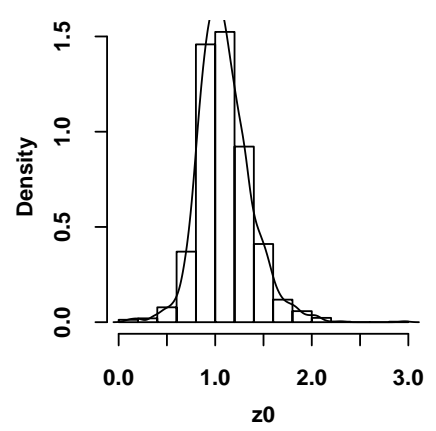

b) Gaussian GLMGEE

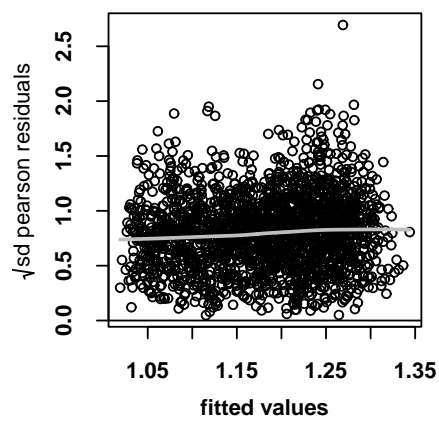

c) Gamma GLMGEE

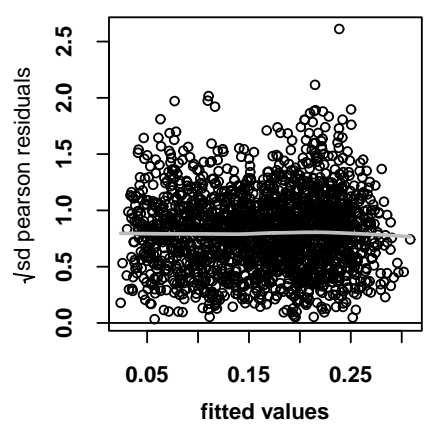

Figure 4. Evaluation of $z_{0 i, s}$ to select the best underlying distribution for the GLMGEE model. b) and c) show the residuals of Eq.(18) assuming a Gaussian distribution with identity link and a Gamma distribution with log link, respectively. The graphs are for a duration of 180 minutes but similar results are obtained for the other three durations. 

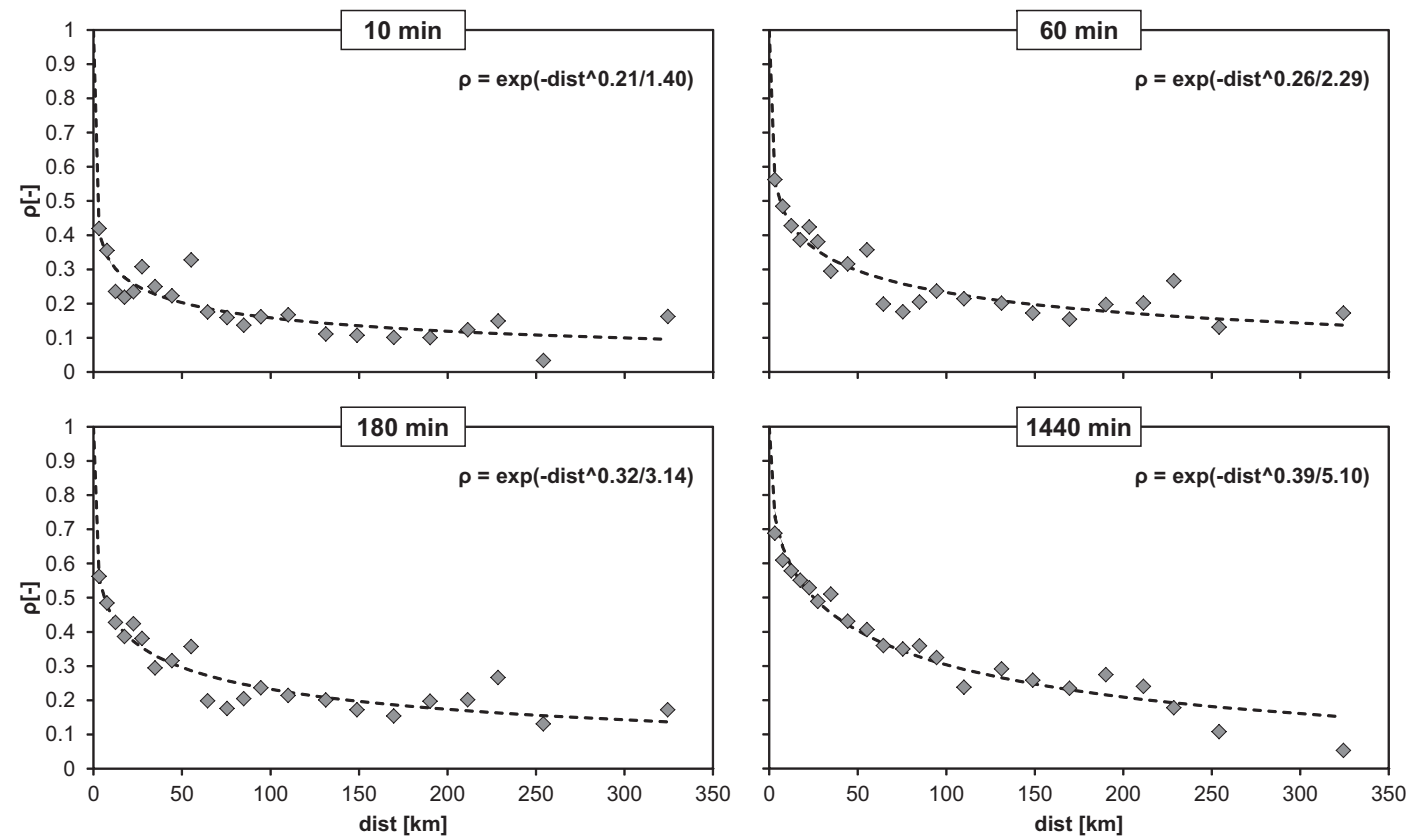

Figure 5. The correlogram for the spatial variation of $\lambda$. Blue dots represents the observed correlation averaged in selected bins, the black line represents the fitted exponential model given in the top left of each graphs.
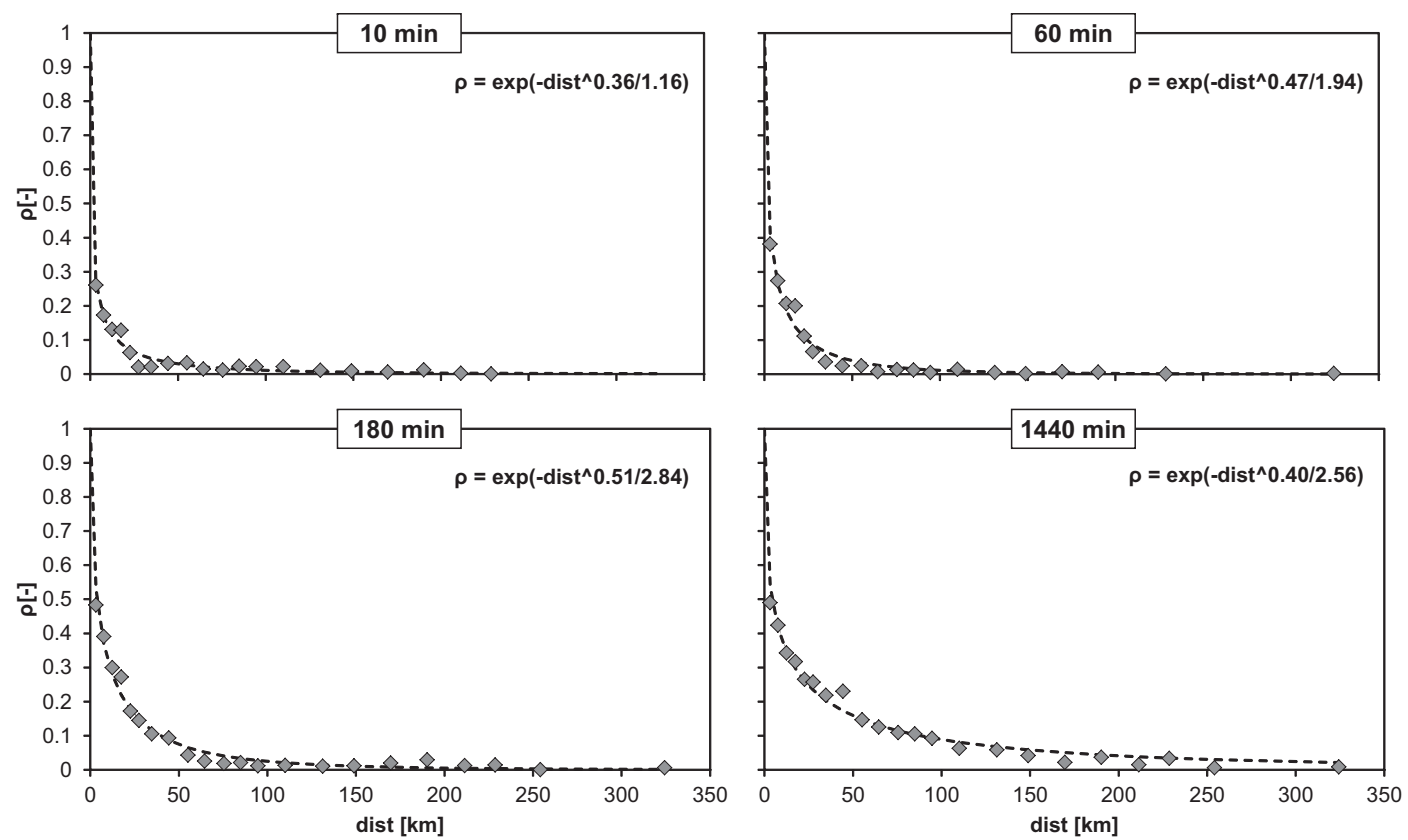

Figure 6. The correlogram for the spatial variation of $\mu$. Blue dots represents the observed correlation averaged in selected bins, the black line represents the fitted exponential model given in the top left of each graphs. 

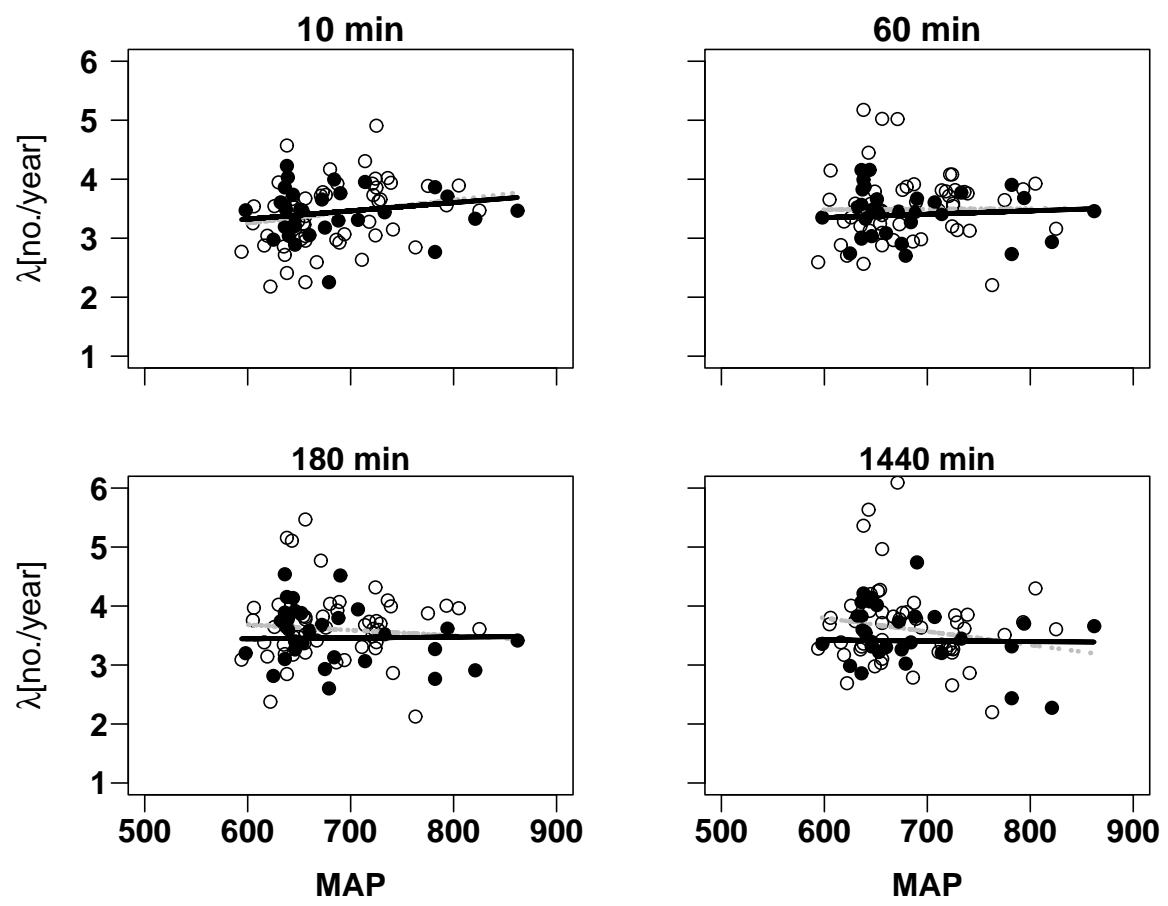

Figure 7. Marginal regional variation of $\lambda$ from a PDS sampling with a spatio-temporal $z_{0}$. OLS and GLS regression are shown in grey and black, respectively. The marked $\lambda$ values are from stations with more than 30 years of observation. 

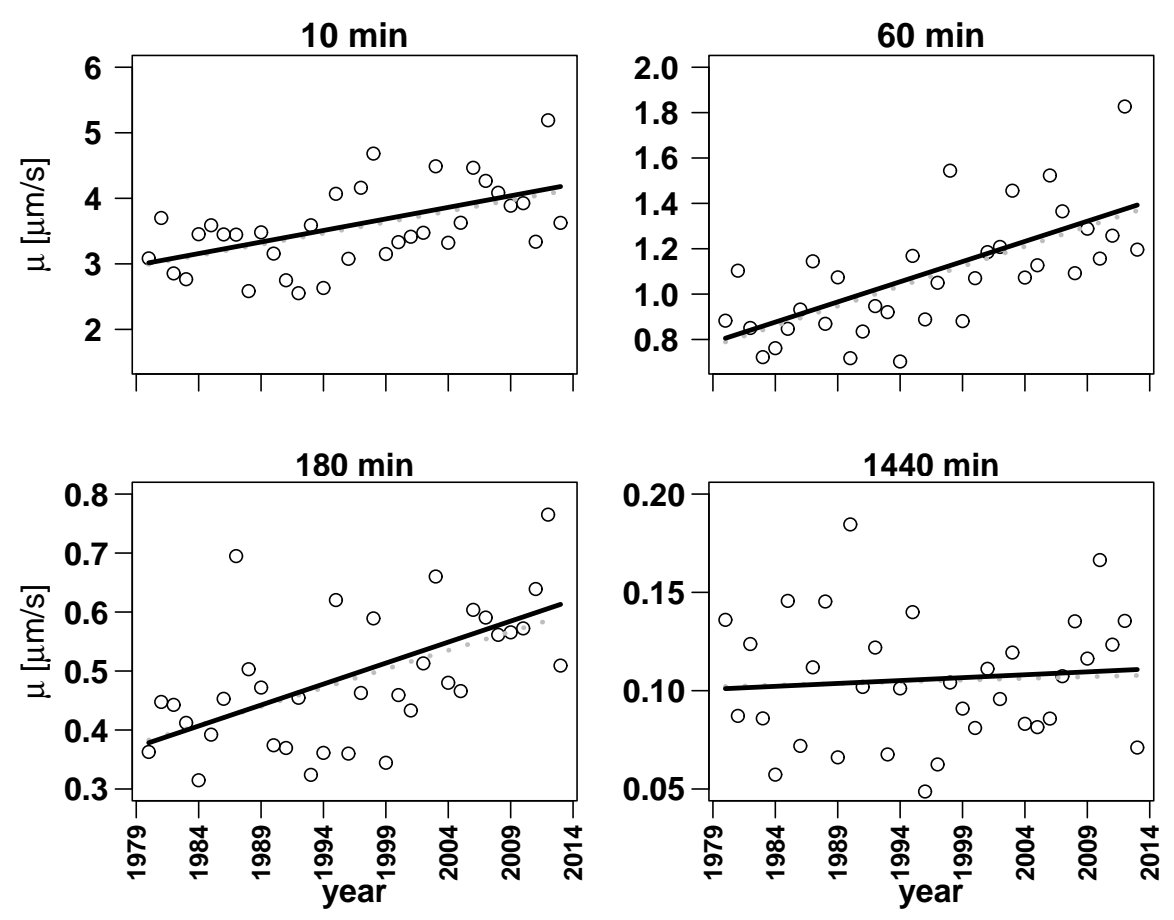

Figure 8. Marginal temporal variation of $\mu$ from a PDS sampling with a spatio-temporal $z_{0}$. OLS (grey line) and GLS (black line) regression estimates are almost identical.
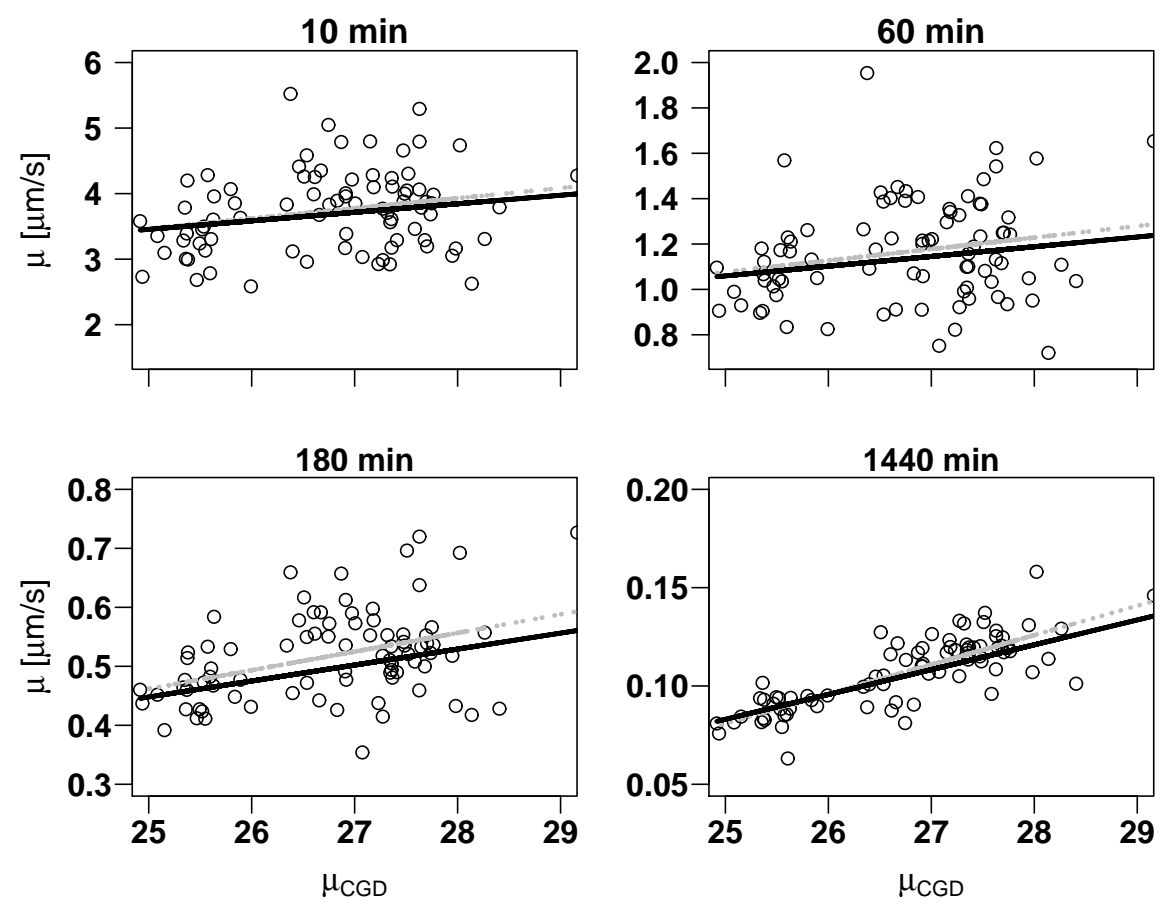

Figure 9. Marginal regional variation of $\mu$ from a PDS sampling with a spatio-temporal $z_{0}$. OLS and GLS regression are shown in grey and black, respectively. 
a) Histogram of $\mu$

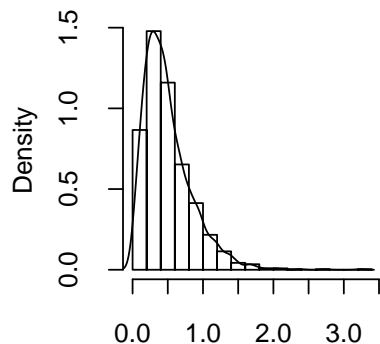

c) Gamma GLMGEE

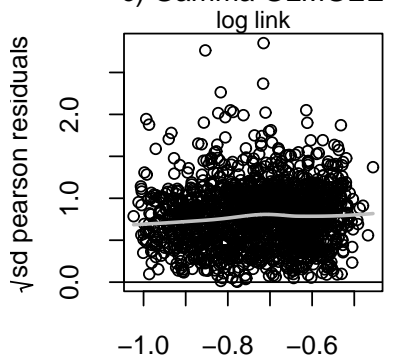

b) Gaussian GLMGEE

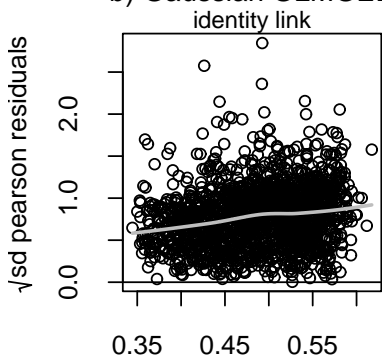

d) Gamma GLMGEE

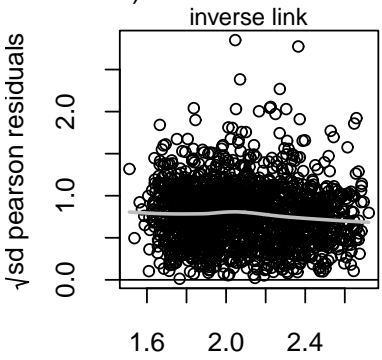

Figure 10. Evaluation of $\mu_{i, s}$ to select the best underlying distribution for the GLMGEE model. b), c) and d) show the residuals of Eq.(24) assuming a Gaussian distribution with identity link, a Gamma distribution with $\log$ link and a Gamma distribution with inverse link, respectively. The graphs are for a duration of 180 minutes. 
Table 1. The estimated GLS parameters in the marginal regional regression models for $z_{0 s}{ }^{\mathrm{a}}$

\begin{tabular}{|c|c|c|c|c|c|c|}
\hline $\begin{array}{l}\text { Duration } \\
{[\mathrm{min}]}\end{array}$ & $\begin{array}{c}a \\
{[\mu \mathrm{m} / \mathrm{s}]}\end{array}$ & $\begin{array}{c}b \\
{[\mu \mathrm{m} / \mathrm{s} / \mathrm{mm}]}\end{array}$ & $p_{b}$ & $\hat{\sigma}_{\delta}^{2}$ & $\mathrm{MSE}_{\varepsilon}$ & $\begin{array}{l}\mathrm{MSE}_{\varepsilon} \\
\text { reduction }\end{array}$ \\
\hline 10 & $\begin{array}{c}4.61 \\
(1.102)\end{array}$ & $\begin{array}{c}0.0028 \\
(0.0015)\end{array}$ & 0.07 & 0.248 & $\begin{array}{c}0.492 \\
(80)\end{array}$ & $9.77 \%$ \\
\hline 60 & $\begin{array}{c}1.71 \\
(0.346)\end{array}$ & $\begin{array}{c}6.5 \cdot 10^{-4} \\
\left(4.8 \cdot 10^{-4}\right)\end{array}$ & 0.18 & 0.022 & $\begin{array}{c}0.041 \\
(80)\end{array}$ & $5.91 \%$ \\
\hline 180 & $\begin{array}{c}0.83 \\
(0.158)\end{array}$ & $\begin{array}{c}3.6 \cdot 10^{-4} \\
\left(2.2 \cdot 10^{-4}\right)\end{array}$ & 0.10 & 0.0050 & $\begin{array}{c}0.0073 \\
(80)\end{array}$ & $3.57 \%$ \\
\hline 1440 & $\begin{array}{c}0.10 \\
(0.037)\end{array}$ & $\begin{array}{c}2.2 \cdot 10^{-4} \\
\left(5.2 \cdot 10^{-5}\right)\end{array}$ & $<0.01$ & $2.8 \cdot 10^{-4}$ & $\begin{array}{c}3.7 \cdot 10^{-4} \\
(80)\end{array}$ & $21.82 \%$ \\
\hline
\end{tabular}

${ }^{a} p_{b}$ measures the significance of $b$, which represents the regression to MAP [mm], see Eq.(16). MSE ${ }_{\varepsilon}$ denotes the Mean Squared Error of the residuals with degrees of freedom given in parenthesis. The $\mathrm{MSE}_{\varepsilon}$ reduction is estimated by comparison with an intercept model. For the regression parameters standard deviation is given in parenthesis.

Table 2. The estimated GLS parameters in the marginal temporal regression models for $z_{0 i}{ }^{\text {a }}$

\begin{tabular}{|c|c|c|c|c|c|c|}
\hline $\begin{array}{l}\text { Duration } \\
\text { [min] }\end{array}$ & $\begin{array}{c}a \\
{[\mu \mathrm{m} / \mathrm{s}]}\end{array}$ & $\begin{array}{c}c \\
{[\mu \mathrm{m} / \mathrm{s} / \text { year }]}\end{array}$ & $p_{c}$ & $\hat{\sigma}_{\delta}^{2}$ & $\mathrm{MSE}_{\varepsilon}$ & $\begin{array}{c}\mathrm{MSE}_{\varepsilon} \\
\text { reduction }\end{array}$ \\
\hline 10 & $\begin{array}{c}4.95 \\
(0.40)\end{array}$ & $\begin{array}{c}0.085 \\
(0.018)\end{array}$ & $<0.01$ & $5.4 \cdot 10^{-4}$ & $\begin{array}{c}0.726 \\
(31)\end{array}$ & $47.43 \%$ \\
\hline 60 & $\begin{array}{c}1.78 \\
(0.13)\end{array}$ & $\begin{array}{c}0.021 \\
(0.0059)\end{array}$ & $<0.01$ & $4.2 \cdot 10^{-4}$ & $\begin{array}{c}0.073 \\
(31)\end{array}$ & $35.07 \%$ \\
\hline 180 & $\begin{array}{c}0.94 \\
(0.060)\end{array}$ & $\begin{array}{c}0.0078 \\
(0.0027)\end{array}$ & - & 0 & $\begin{array}{c}0.014 \\
(31)\end{array}$ & $28.74 \%$ \\
\hline 1440 & $\begin{array}{c}0.21 \\
(0.017)\end{array}$ & $\begin{array}{c}0.0018 \\
\left(7.5 \cdot 10^{-4}\right)\end{array}$ & - & 0 & $\begin{array}{c}7.9 \cdot 10^{-4} \\
(31)\end{array}$ & $26.56 \%$ \\
\hline
\end{tabular}

${ }^{\mathrm{a}} p_{c}$ measures the significance of $c$, which represents the regression to time [year], see Eq.(17). MSE ${ }_{\varepsilon}$ denotes the Mean Squared Error of the residuals with degrees of freedom given in parenthesis. The $\mathrm{MSE}_{\varepsilon}$ reduction is estimated by comparison with an intercept model. For the regression parameters standard deviation is given in parenthesis. 
Table 3. The estimated parameters in the Gaussian GLMGEE models for $z_{0 i, s}$, compared to the two marginal GLS models from Table 1 and Table $2^{\mathrm{a}}$

\begin{tabular}{|c|c|c|c|c|c|c|c|}
\hline $\begin{array}{l}\text { Duration } \\
{[\mathrm{min}]}\end{array}$ & & $\begin{array}{c}a \\
{[\mu \mathrm{m} / \mathrm{s}]}\end{array}$ & $\begin{array}{c}b \\
{[\mu \mathrm{m} / \mathrm{s} / \mathrm{mm}]}\end{array}$ & $p_{b}$ & $\begin{array}{c}c \\
{[\mu \mathrm{m} / \mathrm{s} / \text { year }]}\end{array}$ & $p_{c}$ & $\begin{array}{c}\mathrm{MSE}_{\varepsilon} \\
\text { reduction }\end{array}$ \\
\hline 10 & GLMGEE & $\begin{array}{c}3.79 \\
(0.67)\end{array}$ & $\begin{array}{c}0.0021 \\
(0.0009)\end{array}$ & 0.02 & $\begin{array}{c}0.080 \\
(0.014)\end{array}$ & $<0.01$ & $14.3 \%$ \\
\hline \multirow{3}{*}{60} & marginal GLS & \multirow{3}{*}{$\begin{array}{c}1.50 \\
(0.23)\end{array}$} & $\begin{array}{c}0.0028 \\
(0.0015)\end{array}$ & 0.07 & $\begin{array}{c}0.085 \\
(0.018)\end{array}$ & $<0.01$ & \multirow{3}{*}{$10.0 \%$} \\
\hline & GLMGEE & & $\begin{array}{c}5.3 \cdot 10^{-4} \\
\left(3.1 \cdot 10^{-4}\right)\end{array}$ & 0.08 & $\begin{array}{c}0.018 \\
(0.005)\end{array}$ & $<0.01$ & \\
\hline & marginal GLS & & $\begin{array}{c}6.5 \cdot 10^{-4} \\
\left(4.8 \cdot 10^{-4}\right)\end{array}$ & 0.18 & $\begin{array}{c}0.021 \\
(0.0059)\end{array}$ & 0.01 & \\
\hline 180 & GLMGEE & $\begin{array}{c}0.72 \\
(0.10)\end{array}$ & $\begin{array}{c}3.8 \cdot 10^{-4} \\
\left(1.5 \cdot 10^{-4}\right)\end{array}$ & $<0.01$ & $\begin{array}{c}0.0060 \\
(0.0018)\end{array}$ & $<0.01$ & $7.10 \%$ \\
\hline \multirow{3}{*}{1440} & marginal GLS & & $\begin{array}{c}3.6 \cdot 10^{-4} \\
\left(2.2 \cdot 10^{-4}\right)\end{array}$ & 0.10 & $\begin{array}{c}0.0078 \\
(0.0027)\end{array}$ & - & \multirow{3}{*}{$9.7 \%$} \\
\hline & GLMGEE & $\begin{array}{c}0.044 \\
(0.024)\end{array}$ & $\begin{array}{c}2.6 \cdot 10^{-4} \\
\left(3.0 \cdot 10^{-5}\right)\end{array}$ & $<0.01$ & $\begin{array}{c}0.0013 \\
\left(4.5 \cdot 10^{-4}\right)\end{array}$ & $<0.01$ & \\
\hline & marginal GLS & & $\begin{array}{c}2.2 \cdot 10^{-4} \\
\left(5.2 \cdot 10^{-5}\right)\end{array}$ & $<0.01$ & $\begin{array}{c}0.0018 \\
\left(7.5 \cdot 10^{-3}\right)\end{array}$ & - & \\
\hline
\end{tabular}

${ }^{\mathrm{a}} p_{b}$ measures the significance of $b$, which represents the regression to $M A P[\mathrm{~mm}]$, see Eq.(18). $p_{c}$ measures the significance of $c$, which represents the regression to time [year], see Eq.(18). The MSE $\varepsilon_{\varepsilon}$ reduction is estimated by comparison with an intercept model. For the regression parameters standard deviation is given in parenthesis. 
Table 4. The estimated parameters in the Poisson GLMGEE models for $N_{i, s}$ with a log-link, see Eq. $(21)^{\mathrm{a}}$

\begin{tabular}{lcccc}
\hline & $10 \mathrm{~min}$ & $60 \mathrm{~min}$ & $180 \mathrm{~min}$ & $1440 \mathrm{~min}$ \\
\hline \multirow{2}{*}{ scale of Poisson } & -4.65 & -4.63 & -4.60 & -4.62 \\
\multirow{2}{*}{$\lambda[$ no./year] } & $(0.048)$ & $(0.054)$ & $(0.052)$ & $(0.055)$ \\
& 1.22 & 1.26 & 1.23 & 1.15 \\
& 3.48 & 3.56 & 3.67 & 3.58 \\
& $(0.17)$ & $(0.19)$ & $(0.19)$ & $(0.20)$ \\
\hline
\end{tabular}

${ }^{\mathrm{a}} a$ represents the model intercept, see Eq.(21). The scale measures the dispersion of the Poisson distribution, see Gregersen et al. [2013a]. $\lambda$ is predicted from the model using an observation period of one year $\left(l_{i, s}=365\right.$ days $)$. Uncertainty on the estimates is given in parenthesis. 
Table 5. The estimated parameters in the Gamma GLMGEE models for $\mu_{0 i, s}$, compared to the two marginal GLS models ${ }^{\mathrm{a}}$

\begin{tabular}{|c|c|c|c|c|c|c|c|c|}
\hline $\begin{array}{l}\text { Duration } \\
{[\mathrm{min}]}\end{array}$ & & $a$ & $b$ & $p_{b}$ & $c$ & $p_{c}$ & $\begin{array}{c}\text { Gamma } \\
\text { scale }\end{array}$ & $\begin{array}{l}\mathrm{MSE}_{\varepsilon} \\
\text { reduction }\end{array}$ \\
\hline 10 & GLMGEE & $\begin{array}{c}0.51 \\
(0.19)\end{array}$ & $\begin{array}{l}-7.0 \cdot 10^{-3} \\
\left(7.1 \cdot 10^{-3}\right)\end{array}$ & 0.32 & $\begin{array}{l}-2.4 \cdot 10^{-3} \\
\left(5.8 \cdot 10^{-4}\right)\end{array}$ & $<0.01$ & 0.49 & \multirow{5}{*}{$3.07 \%$} \\
\hline \multirow{5}{*}{60} & marginal GLS & & $\begin{array}{c}0.13 \\
(0.079)\end{array}$ & 0.10 & $\begin{array}{c}0.035 \\
\left(9.8 \cdot 10^{-3}\right)\end{array}$ & $<0.01$ & & \\
\hline & reduced GLMGEE & $\begin{array}{c}0.32 \\
(0.016)\end{array}$ & & & $\begin{array}{l}-2.4 \cdot 10^{-3} \\
\left(5.8 \cdot 10^{-4}\right)\end{array}$ & $<0.01$ & 0.49 & \\
\hline & GLMGEE & $\begin{array}{c}1.24 \\
(0.64)\end{array}$ & $\begin{array}{c}-0.020 \\
(0.024)\end{array}$ & 0.93 & $\begin{array}{c}-0.014 \\
\left(2.6 \cdot 10^{-3}\right)\end{array}$ & $<0.01$ & \multirow[t]{2}{*}{0.53} & \\
\hline & marginal GLS & & $\begin{array}{c}0.043 \\
(0.031)\end{array}$ & 0.17 & $\begin{array}{c}0.018 \\
\left(3.7 \cdot 10^{-3}\right)\end{array}$ & $<0.01$ & & \\
\hline & reduced GLMGEE & $\begin{array}{c}1.19 \\
(0.064)\end{array}$ & & & $\begin{array}{c}-0.014 \\
\left(2.6 \cdot 10^{-3}\right)\end{array}$ & $<0.01$ & 0.53 & $9.64 \%$ \\
\hline \multirow[t]{3}{*}{180} & GLMGEE & $\begin{array}{c}4.83 \\
(1.32)\end{array}$ & $\begin{array}{c}-0.084 \\
(0.051)\end{array}$ & 0.10 & $\begin{array}{c}-0.026 \\
\left(6.0 \cdot 10^{-3}\right)\end{array}$ & $<0.01$ & 0.49 & $7.99 \%$ \\
\hline & marginal GLS & & $\begin{array}{c}0.027 \\
(0.012)\end{array}$ & 0.02 & $\begin{array}{c}7.1 \cdot 10^{-3} \\
\left(1.7 \cdot 10^{-3}\right)\end{array}$ & $<0.01$ & & \multirow{4}{*}{$5.64 \%$} \\
\hline & reduced GLMGEE & $\begin{array}{c}2.61 \\
(0.15)\end{array}$ & & & $\begin{array}{c}-0.026 \\
\left(5.9 \cdot 10^{-3}\right)\end{array}$ & $<0.01$ & 0.50 & \\
\hline \multirow[t]{3}{*}{1440} & GLMGEE & $\begin{array}{l}47.77 \\
(7.76)\end{array}$ & $\begin{array}{l}-1.39 \\
(0.29)\end{array}$ & $<0.01$ & $\begin{array}{l}-0.019 \\
(0.052)\end{array}$ & 0.71 & 0.53 & \\
\hline & marginal GLS & & $\begin{array}{c}0.013 \\
\left(2.6 \cdot 10^{-3}\right)\end{array}$ & $<0.01$ & $\begin{array}{c}2.9 \cdot 10^{-4} \\
\left(5.6 \cdot 10^{-4}\right)\end{array}$ & 0.60 & & \\
\hline & reduced GLMGEE & $\begin{array}{l}47.65 \\
(7.79)\end{array}$ & $\begin{array}{l}-1.40 \\
(0.30)\end{array}$ & $<0.01$ & & & 0.53 & $17.8 \%$ \\
\hline
\end{tabular}

${ }^{\mathrm{a}}$ Due to the inverse link function of the GLMGEE model, parameters cannot be directly compared but the significance can. In the reduced GLMGEE non-significant terms have been excluded. Uncertainty on the parameter estimates is given in parenthesis. $\mathrm{MSE}_{\varepsilon}$ denotes the Mean Squared Error of the residuals. The $\mathrm{MSE}_{\varepsilon}$ reduction is estimated by comparison with an intercept model. 
Table 6. Estimations of $L_{c v}$ and $\kappa^{a}$

\begin{tabular}{lcccc}
\hline & $10 \min$ & $60 \min$ & $180 \min$ & $1440 \min$ \\
\hline \multirow{2}{*}{$L_{c v}$} & 0.53 & 0.55 & 0.54 & 0.54 \\
& $\left(7.1 \cdot 10^{-5}\right)$ & $\left(2.7 \cdot 10^{-4}\right)$ & $\left(4.0 \cdot 10^{-4}\right)$ & $\left(1.5 \cdot 10^{-4}\right)$ \\
$\kappa$ & -0.12 & -0.19 & -0.16 & -0.15 \\
& $\left(8.8 \cdot 10^{-4}\right)$ & $\left(2.9 \cdot 10^{-3}\right)$ & $\left(4.6 \cdot 10^{-3}\right)$ & $\left(1.8 \cdot 10^{-3}\right)$ \\
\hline
\end{tabular}

${ }^{\mathrm{a}}$ Uncertainty on the parameter estimates is given in parenthesis.

Table 7. Estimations of design intensities with a return period of 10 years, uncertainty is given in parenthesis $^{\mathrm{a}}$

\begin{tabular}{lcccccc}
\hline & $\begin{array}{c}\text { MAP } \\
{[\mathrm{mm}]}\end{array}$ & $\begin{array}{c}\mu_{C G D} \\
{[\mathrm{~mm}]}\end{array}$ & $\begin{array}{c}10 \mathrm{~min} \\
{[\mu \mathrm{m} / \mathrm{s}]}\end{array}$ & $\begin{array}{c}60 \mathrm{~min} \\
{[\mu \mathrm{m} / \mathrm{s}]}\end{array}$ & $\begin{array}{c}180 \mathrm{~min} \\
{[\mu \mathrm{m} / \mathrm{s}]}\end{array}$ & $\begin{array}{c}1440 \mathrm{~min} \\
{[\mu \mathrm{m} / \mathrm{s}]}\end{array}$ \\
\hline Madsen et al. (in prep) & 707 & 25.5 & $\begin{array}{c}21.30 \\
(1.83)\end{array}$ & $\begin{array}{c}6.91 \\
(0.94)\end{array}$ & $\begin{array}{c}2.99 \\
(0.35)\end{array}$ & $\begin{array}{c}0.61 \\
(0.052)\end{array}$ \\
Eq.(25) with i=1996 & \multirow{2}{*}{707} & 25.5 & 20.00 & 6.59 & 2.93 & 0.59 \\
& & & $(0.90)$ & $(0.50)$ & $(0.26)$ & $(0.032)$ \\
Eq.(25) with i=2005 & 707 & 25.5 & 21.90 & 7.42 & 3.20 & 0.60 \\
& & & $(0.97)$ & $(0.58)$ & $(0.29)$ & $(0.032)$ \\
Madsen et al. (in prep) & 660 & 27.4 & 20.99 & 6.84 & 3.21 & 0.69 \\
& & & $(1.81)$ & $(0.93)$ & $(0.38)$ & $(0.062)$ \\
Eq.(25) with i=1996 & \multirow{2}{*}{660} & 27.4 & 19.93 & 6.57 & 3.05 & 0.68 \\
& & & $(0.90)$ & $(0.50)$ & $(0.28)$ & $(0.045)$ \\
Eq.(25) with i=2005 & \multirow{2}{*}{660} & 27.4 & 21.84 & 7.39 & 3.36 & 0.69 \\
& & & $(0.97)$ & $(0.58)$ & $(0.31)$ & $(0.045)$ \\
\hline
\end{tabular}

${ }^{\mathrm{a}}$ The selected locations correspond to the two largest cities in Denmark (Aarhus and Copenhagen). 